\title{
Review
}

\section{Induced Pluripotent Stem Cells in Huntington's Disease Research: Progress and Opportunity}

\author{
Adelaide Tousley and Kimberly B. Kegel-Gleason* \\ Department of Neurology, Massachusetts General Hospital, Charlestown, MA, USA
}

\begin{abstract}
Induced pluripotent stem cells (iPSCs) derived from controls and patients can act as a starting point for in vitro differentiation into human brain cells for discovery of novel targets and treatments for human disease without the same ethical limitations posed by embryonic stem cells. Numerous groups have successfully produced and characterized Huntington's disease (HD) iPSCs with different CAG repeat lengths, including cells from patients with one or two HD alleles. HD iPSCs and the neural cell types derived from them recapitulate some disease phenotypes found in both human patients and animal models. Although these discoveries are encouraging, the use of iPSCs for cutting edge and reproducible research has been limited due to some of the inherent problems with cell lines and the technological differences in the way laboratories use them. The goal of this review is to summarize the current state of the HD iPSC field, and to highlight some of the issues that need to be addressed to maximize their potential as research tools.
\end{abstract}

Keywords: Huntingtin, Huntington's disease, HTT, induced neuron, induced pluripotent stem cell, neural stem cell, neurodegenerative disorder

\section{INTRODUCTION}

Since their development in 2006, induced pluripotent stem cells (iPSCs) have generated excitement due to their potential to produce appropriate cell models to facilitate discovery of novel targets and treatments for human disease [1]. iPSCs derived from controls and patients can act as a starting point for in vitro differentiation into human brain cells without the same ethical limitations posed by embryonic stem cells. The first human Huntington's disease (HD) iPSCs with mutations of $54 \mathrm{CAG}$ and $72 \mathrm{CAG}$ repeats in

\footnotetext{
*Correspondence to: Kimberly Kegel-Gleason, Assistant Professor in Neurology, Massachusetts General Hospital and Harvard Medical School, 114 16th Street, Room 2001, Charlestown, MA 02129, USA. Tel.: +1 617724 8754; E-mail: kegel@helix.mgh.harvard.edu.
}

the huntingtin gene were created from HD patient fibroblasts in 2008 by Park et al. using retroviral induction of four pluripotency factors: cMyc, Klf4, Oct4, and Sox2 [2]. Since then, numerous groups have successfully produced and characterized iPSCs with different CAG repeat lengths, including cells from patients with one or two HD alleles. HD iPSCs and the neural cell types derived from them recapitulate some disease phenotypes found in both human patients and animal models. Although these discoveries are encouraging, the use of iPSCs for cutting edge and reproducible research has been limited due to some of the inherent problems with cell lines and the technological differences in the way laboratories use them. The goal of this review is to summarize the current state of the HD iPSC field, and to highlight some of the issues that need to be addressed to maximize their potential as research tools (Fig. 1). 


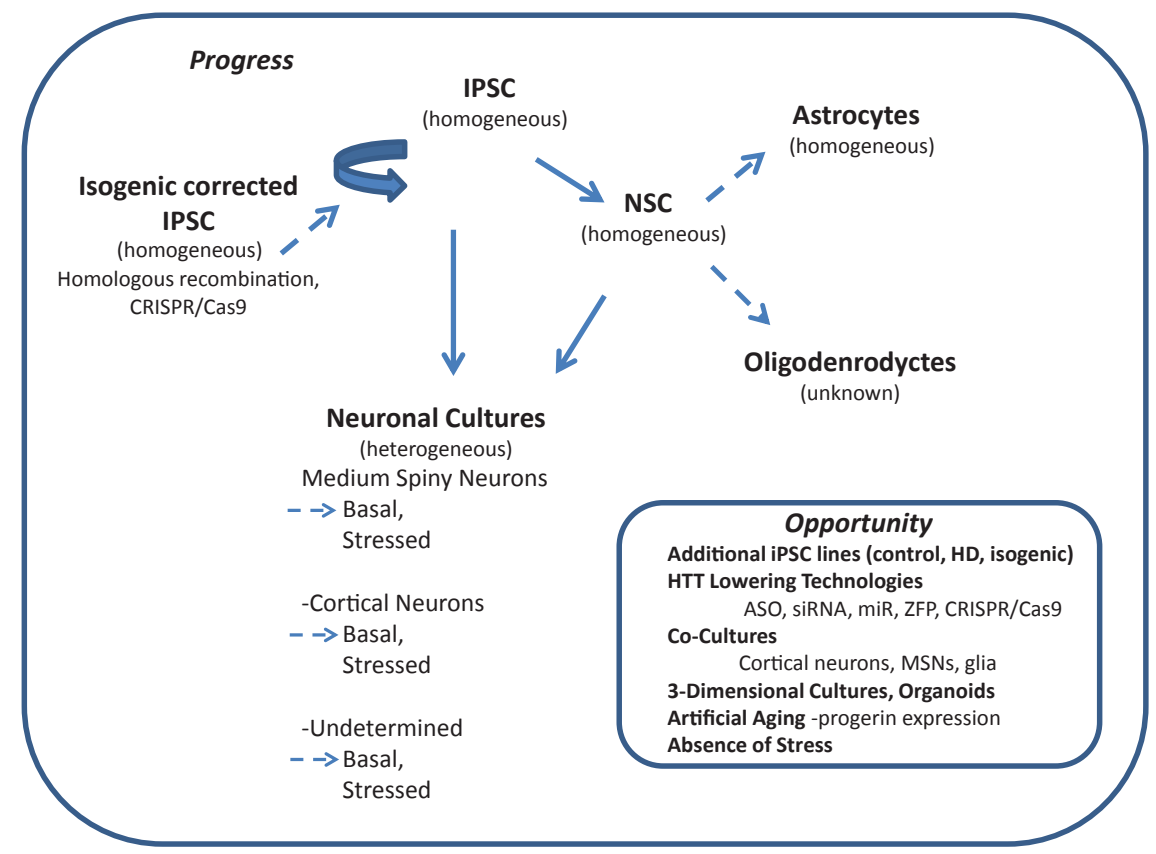

Fig. 1. Induced pluripotent stem cells (iPSC) in Huntington's disease research: progress and opportunity. Schematic shows cell types of the neural lineage that can be differentiated from iPSCs. The relative purity attainable of differentiated cultures is indicated in parenthesis (homogeneous or heterogeneous). Differentiated cultures are rarely $100 \%$ pure but may reach $95 \%$ homogeneity depending on cell type. Neuronal cultures often contain significant numbers of glia including Nestin-positive neural stem cells (NSCs), astrocytes and oligodendrocytes (heterogeneous). Dotted arrows highlight areas where more studies are needed.

\section{The current inventory of HD iPSCs}

Early efforts at reprogramming adult cells to iPSCs relied upon lentiviral [3] or retroviral [1] delivery of cDNAs encoding pluripotency factors [4]. iPSCs have been successfully created from a variety of somatic cell types including fibroblasts [1,3], blood cells [5, 6], renal epithelial cells [7], and keratinocytes $[8,9]$. Several reviews discuss the history and recent advances in reprogramming methods used to produce human iPSCs [10-13]. At present, the best characterized HD iPSC lines have been produced from patient fibroblasts using lentivirus [14-16] or retrovirus [2, 17-28] to express a combination of pluripotency factors, including: Oct3/4, Klf-4, Sox2, c-Myc, SSEA4, LIN-28, NANOG, and p53 shRNA (to increase efficiency). However, the potential for off-target effects due to random viral insertions motivated scientists to develop novel non-integrating approaches for delivery including Sendai-virus [29], adenovirus [30] and episomal vectors [6, 31], as well as RNA transfection [32], protein [33], and small molecule [34, 35] based methods [4]. More recently, HD researchers have created and begun to characterize cells produced using non-integrating, episomal vectors for induction of pluripotency [36-42].

Numerous iPSC lines exist with CAG repeats in the range of wild-type to that of HD in the Huntingtin gene (HTT) (from 17 CAGs to 180 CAGs) [2, 14-28, 36-43]. Many of these cell lines were created by the HD iPSC Consortium and are available through the newly established NINDS Human Cell and Data Repository (NHCPR) including 8 unaffected and 18 HD iPCS lines (the catalog for cell lines can be viewed at the following website: https://stemcells.nindsgenetics.org/). The best described HD iPSC line called HD4 was produced by Park et al. (2008) and contains 72 CAGs [2, 17-20, 23-25, 28]. HD4 was used by the Ellerby laboratory to create two cell lines corrected at the HD locus to 21 CAGs by homozygous recombination [17]. HD4 was also used to create an HD allelic series with 21, 72 and 97 CAGs using gene editing employing the CRISPR/Cas9 system along with an antibody screen to confirm the presence of an expanded polyglutamine region in cell lines [44]. These cell lines together are very useful because they offer an isogenic background on which to delineate effects of 
the HD mutation. Although isogenic lines are a "gold standard" for a well-controlled iPSC experiment, the inherent variability that has been found among control iPSCs substantiates a need for more isogenic lines from additional HD iPSCs.

iPSCs derived from individuals with juvenile onset HD (>60 CAGs) have been used more frequently for genomic and proteomic studies than iPSCs from individuals with adult onset HD (39-60 CAG) [2, 14-28, 36-43]. However, only about $5 \%$ of HD patients have a juvenile onset (prior to age 20) form of the disease, with associated CAG repeat lengths greater than 60 [45-47]. Tables $1 \& 2$ show summaries of gene expression and protein changes based upon available data sets. The majority of reported work with iPSCs from those with adult onset HD has been with a single cell line derived by the HD iPSC Consortium in $2012[15,36]$. This line has 60 CAG repeats which is at the high end of the CAG spectrum for adult onset HD [46, 47]. Additional cell lines with repeats ranging from 43-60 CAGs have been described, they are less well characterized [22, 26, 39, 40, 42, 43]. This is likely in part due to the greater ease of detection of mutant huntingtin protein with longer polyglutamine repeats using antibodies that preferentially recognize extended polyglutamine stretches, and the possibility that longer CAG expansions may give more robust changes, as they do in animal models. At present no iPSCs have been produced from patients bearing "intermediate" CAG repeat lengths (27-35 CAGs) or patients with 36-39 CAGs and reduced disease penetrance. Future work with iPSC derived neuronal cells could provide insight into the molecular changes underlying the behavioral changes identified in intermediate repeat length patients [48], and the differences in disease penetrance with low repeat lengths.

\section{Search for phenotypes unveils numerous $C A G$ repeat length dependent and independent properties}

Several common phenotypes exist for neural stem cells (NSCs) (also called neural precursor cells (NPCs)) and neuronal cultures differentiated from adult and juvenile HD iPSCs. NSCs from both adult and juvenile-onset patients have decreased metabolic rate (respiratory capacity or ATP/ADP ratio) [15, 17, 19], reduced filamentous actin protein and cellcell adhesion [15], as well as parallel changes in gene expression compared to NSCs from controls of genes related to nervous system development, cell assembly and organization [15]. HD neuronal cultures derived from both adult and juvenile-onset iPSCs likewise have increased levels of cell death, caspase 3/7 expression in response to BDNF withdrawal, and altered gene expression in pathways related to cell function/signaling and tissue development [15]. One caveat, however, is that differentiated neuronal cultures are by nature composed of a heterogeneous mixture of cell types and the cell death discovered in this study was not demonstrated to be specific to neurons.

Some unique differences were identified when NSCs from adult onset HD iPSCs were compared to those from juvenile onset HD (Tables $1 \& 2$ ). Pathway analysis of gene array data showed alterations in axonal guidance in NSCs from juvenile HD (72, 109 and 180 CAGs) that were not present in NSCs from those with adult onset (60 CAGs) $[15,19]$. The axon guidance changes were further associated with altered netrin and netrin receptor expression in 72 CAG NSCs [19]. Analysis of gene array data also indicated the presence of alterations in calcium signaling in an HD NSC line with 60 CAGs, but not in ones with 109 or 180 CAGs [15]. These changes in gene expression may have functional relevance in corresponding iPSC induced neuronal cultures: increasing glutamate levels was associated with increased calcium dyshomeostasis and cell death in neuronal cultures with $60 \mathrm{CAGs}$ but not in those with 180 CAGs [15]. As mentioned above, neuronal cultures were heterogeneous and these changes also were not demonstrated to be specific to neurons. But, altered calcium signaling after glutamate treatment was also observed in low repeat (37 and 51 CAGs) embryonic stem cell (ESC)-derived forebrain neuronal cultures [49]. Finally, Mattis et al. (2015) identified a Nestin-positive cell population sensitive to BDNF-withdrawal induced cell death that was present only in neuronal cultures from juvenile-onset cell lines (109 and 180 CAGs) but not adult onset (60 CAGs) [36].

Phenotypes that may be relevant to disease have been identified in naïve and differentiated HD iPSCs. These include conditions related to altered cell growth [18, 24], adhesion [15, 17], differentiation $[18,36]$, protein clearance (proteasomal, autophagic) $[15,16,25,40]$, survival $[15,17-19,36,38]$, oxidative stress/antioxidant response [18, 37, 41], metabolism [14, 15, 17, 19], growth factor signaling $[15,17,20,28,36,41]$ mitochondrial fragmentation [14], and electrophysiological properties [15]. Tables 3 \& 4 list known phenotypes of HD cell lines. 


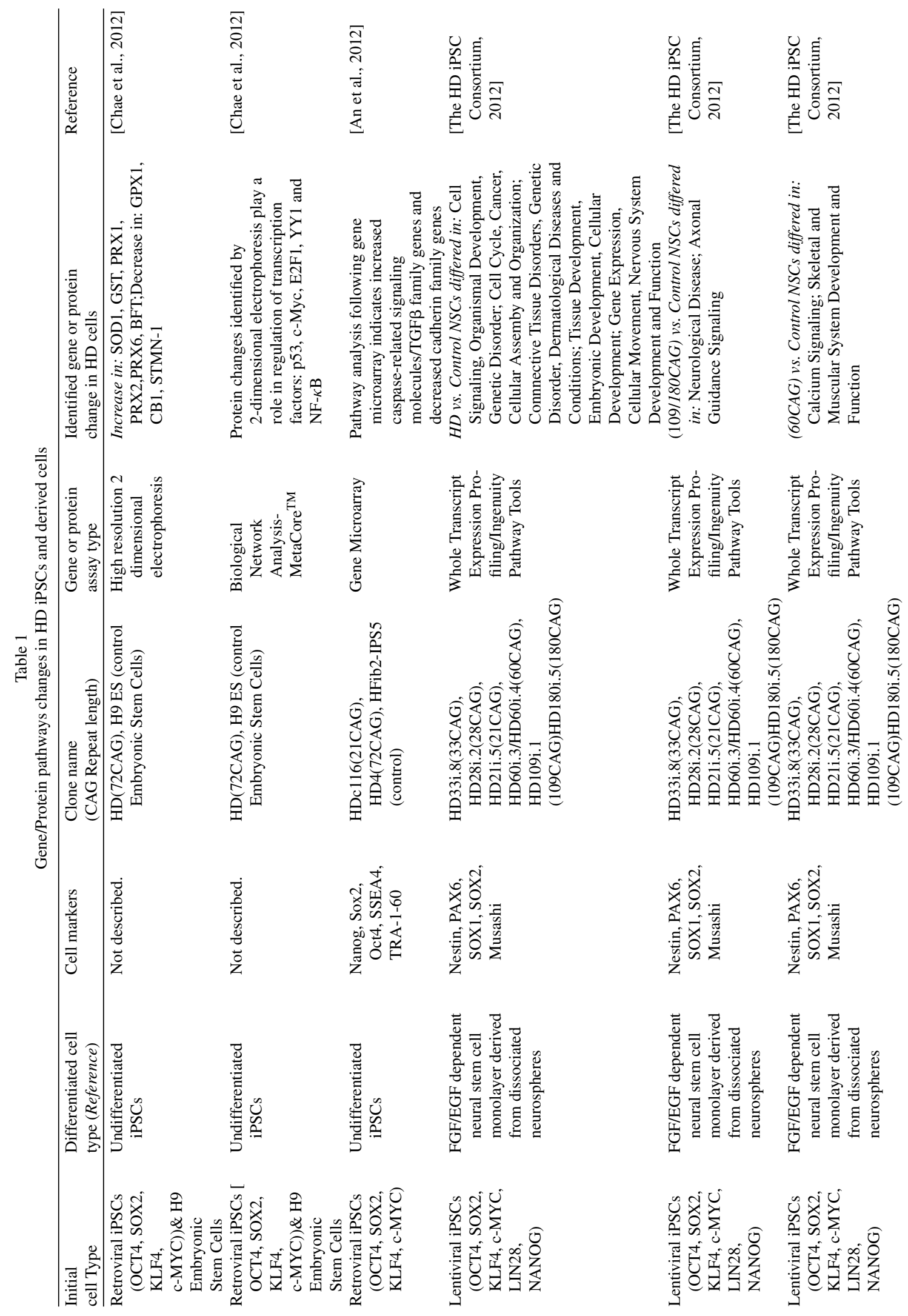



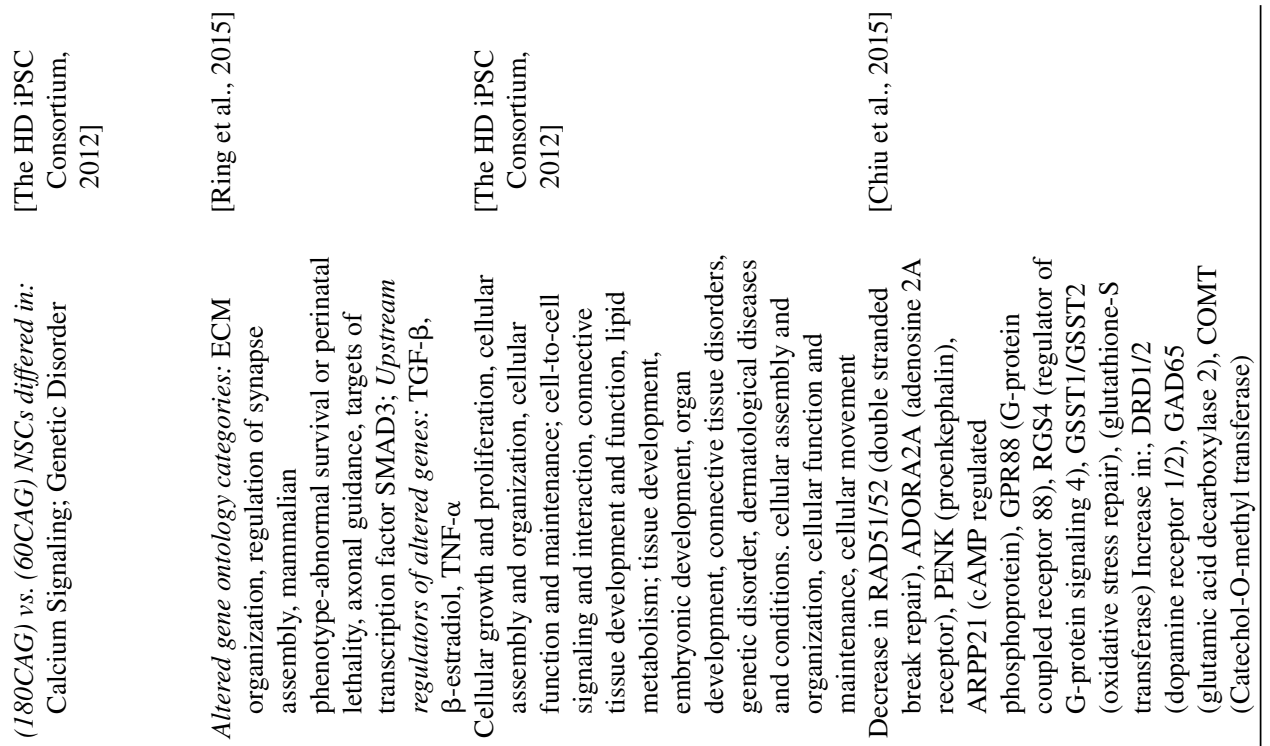

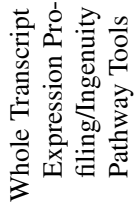

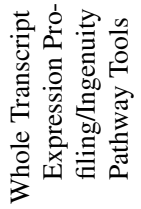

焉
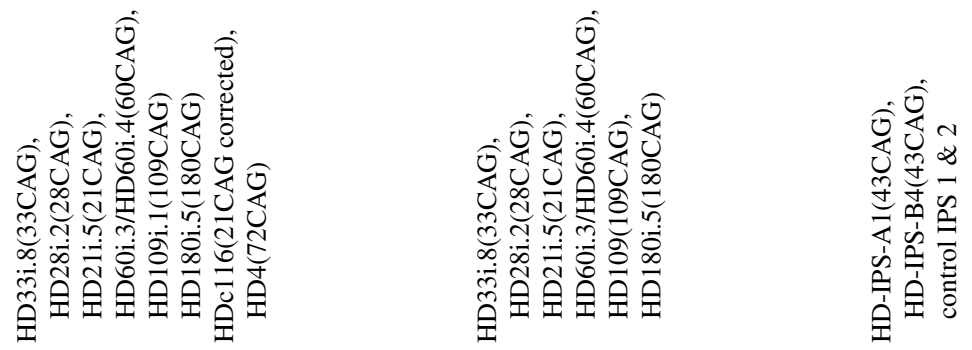

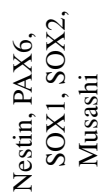

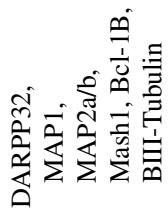

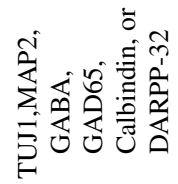
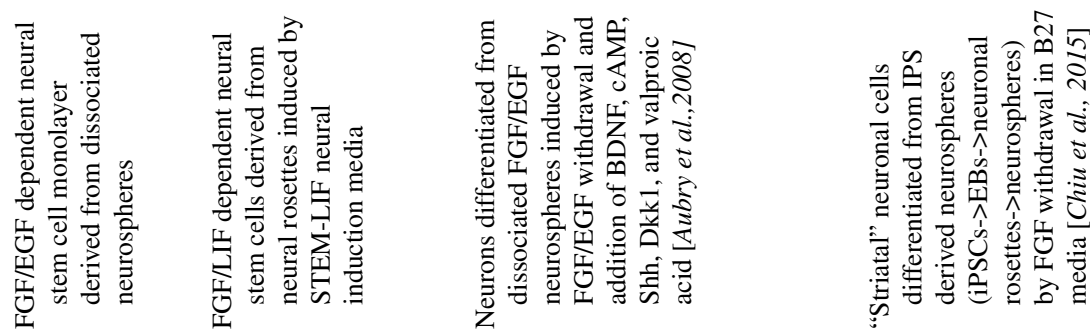

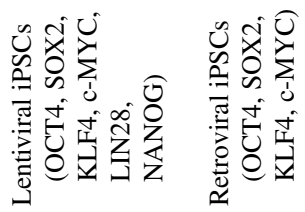
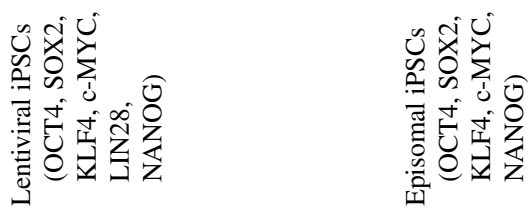


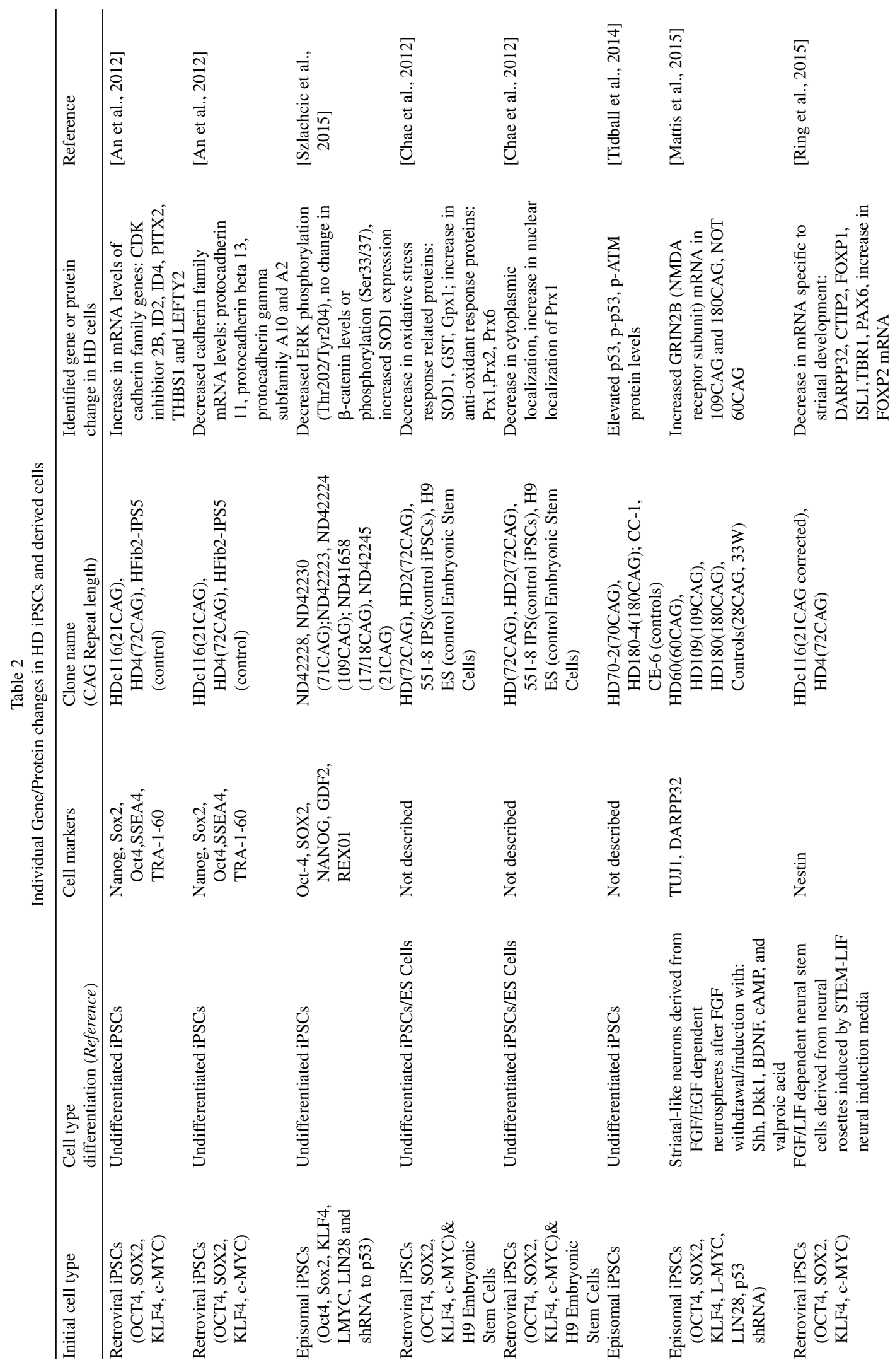



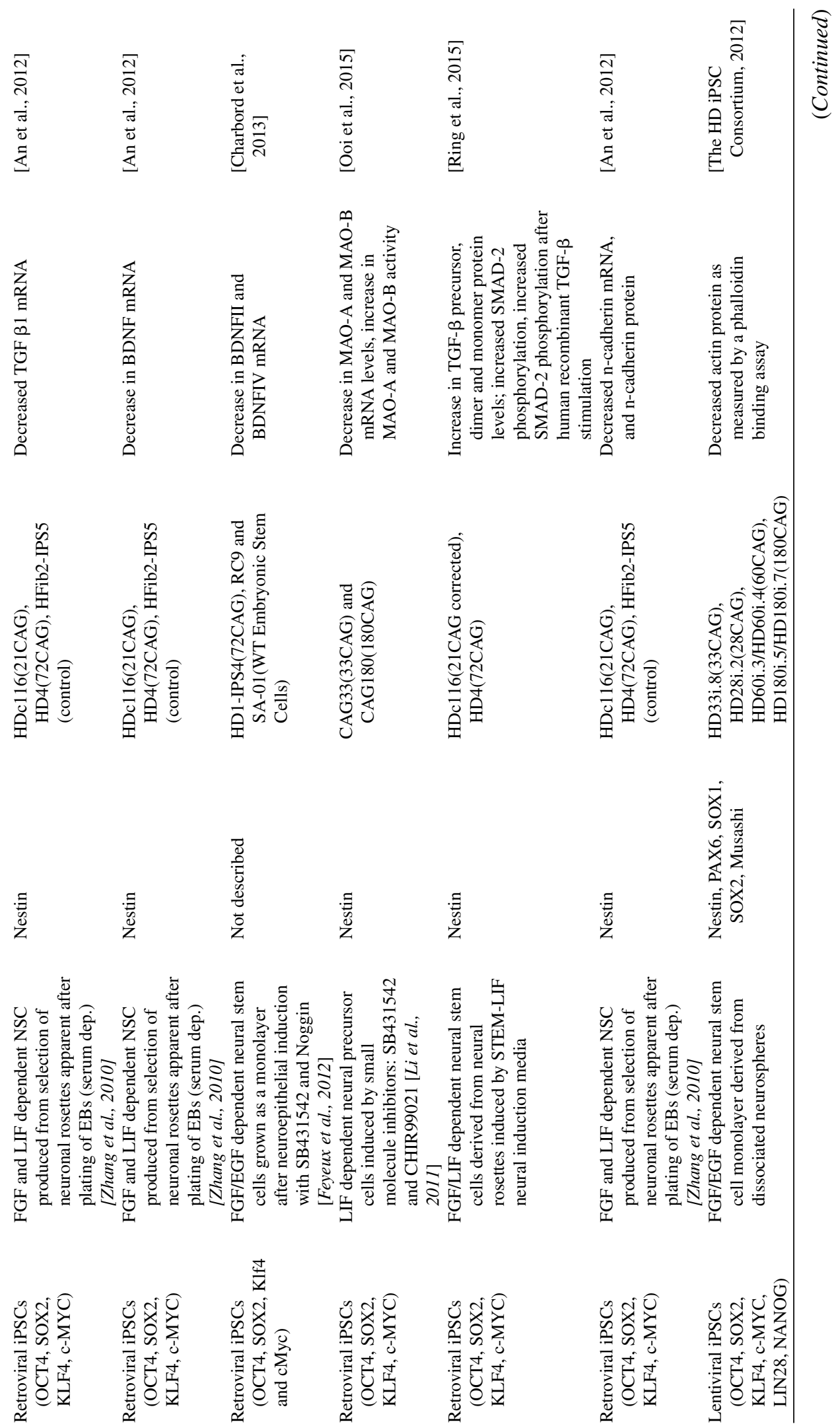


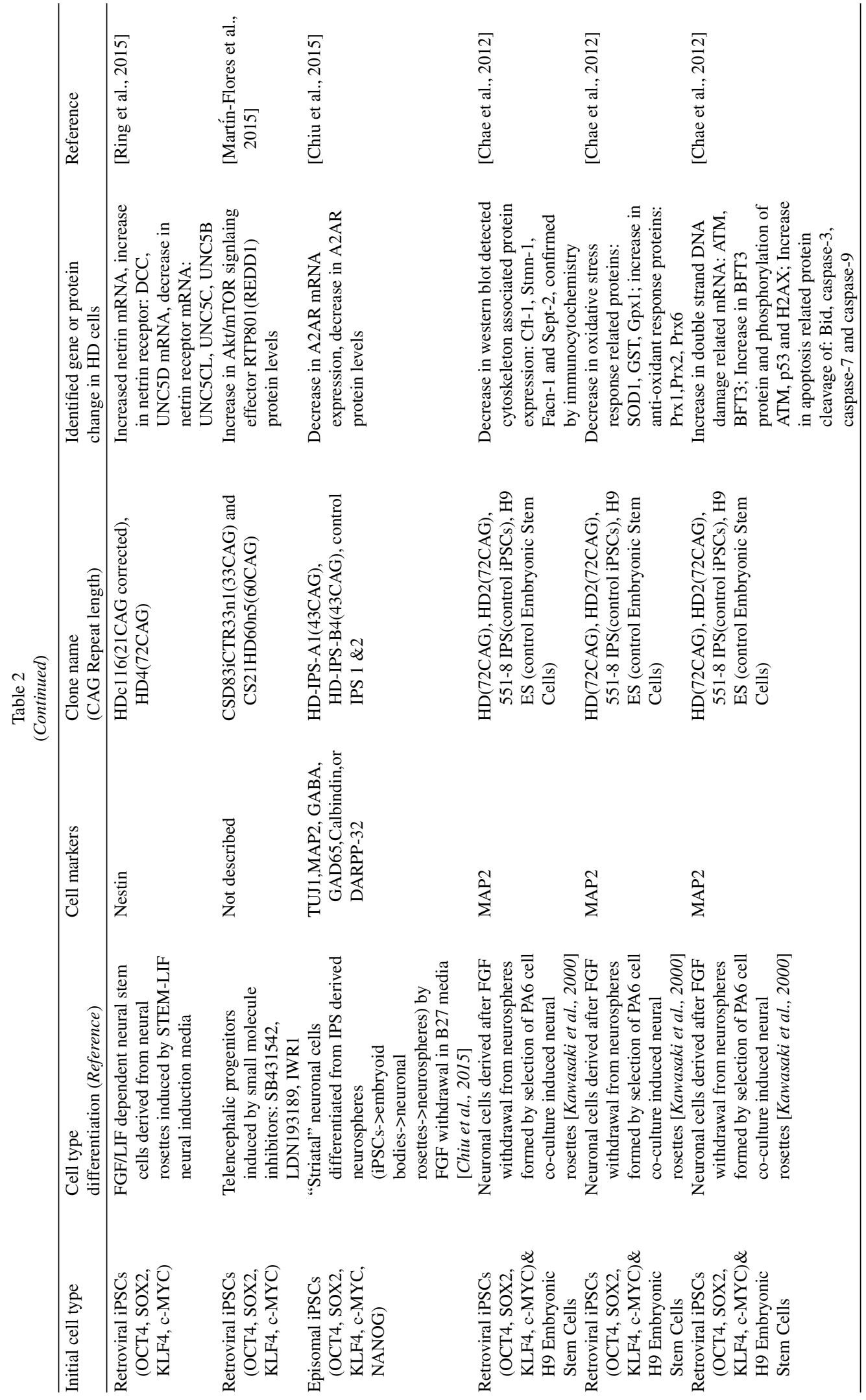




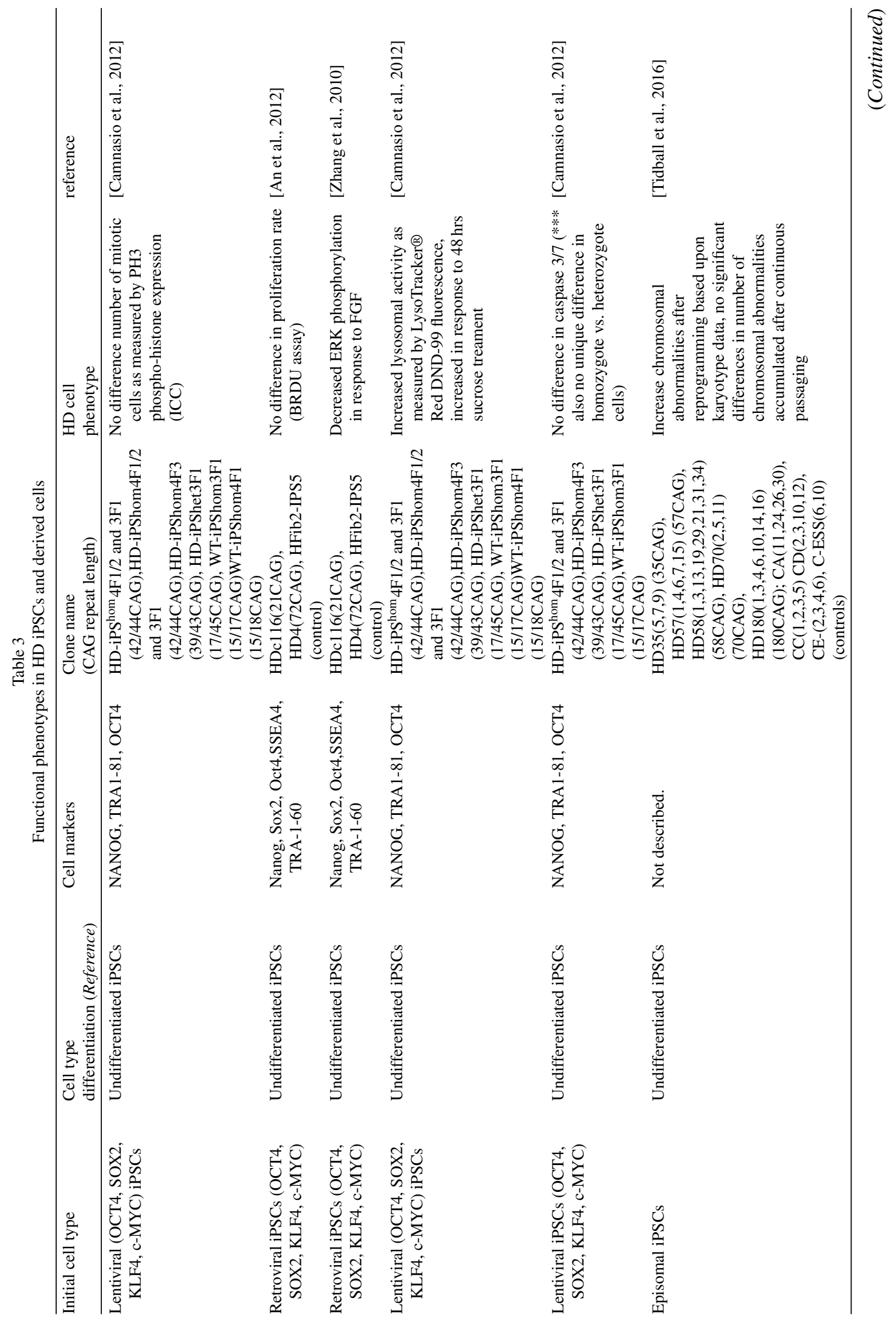




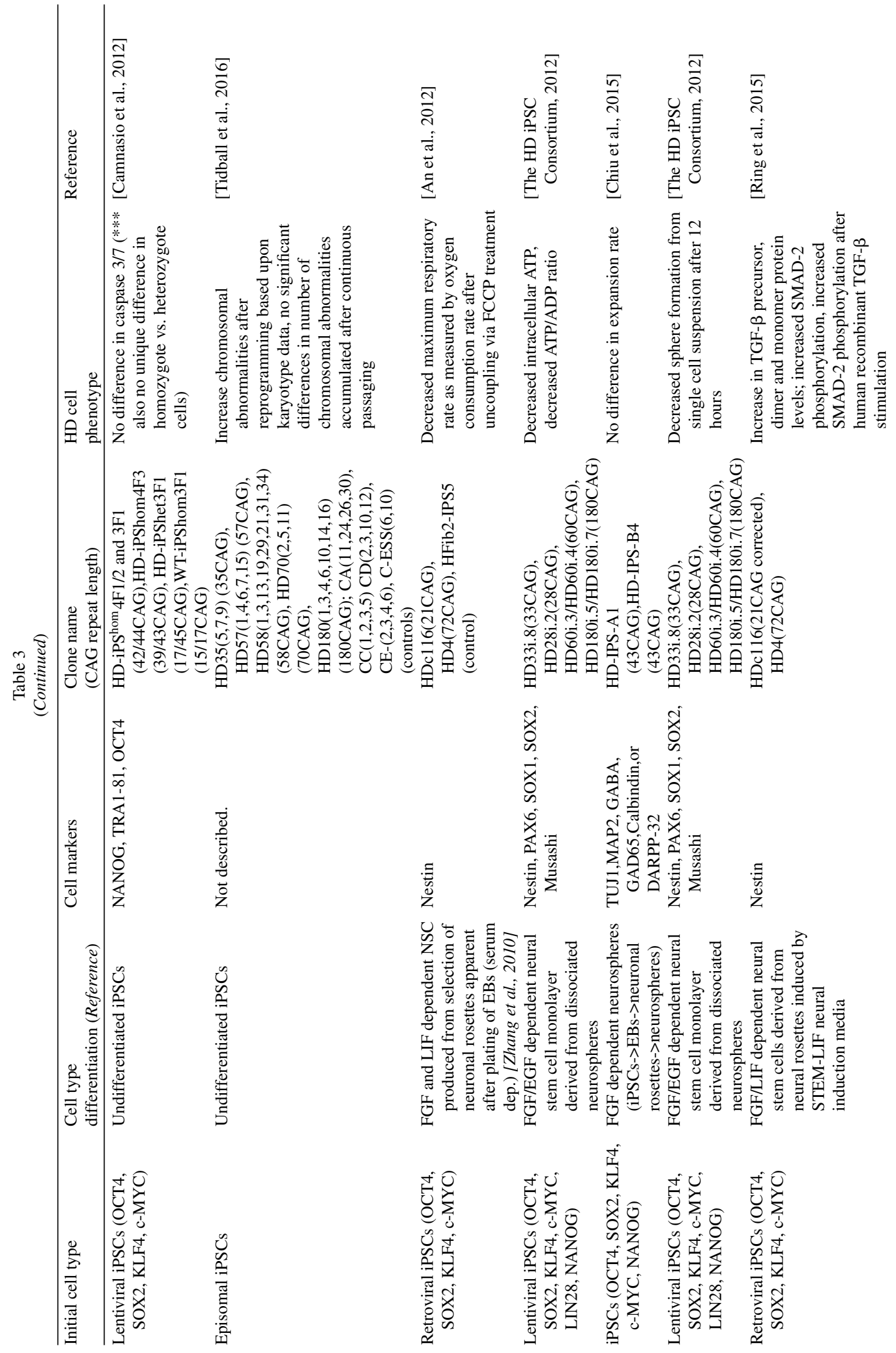




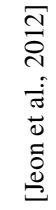

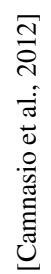

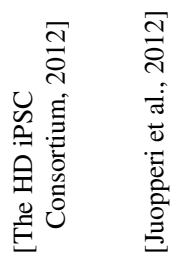

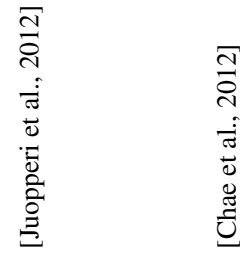

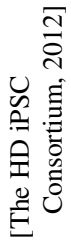

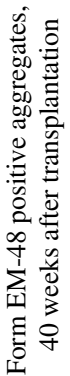

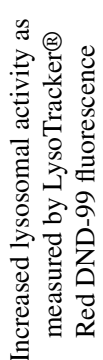
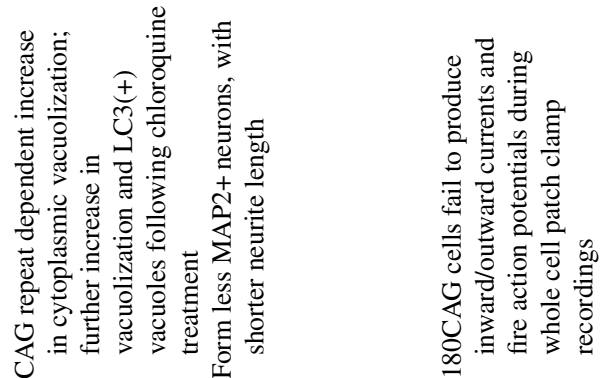

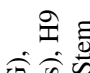
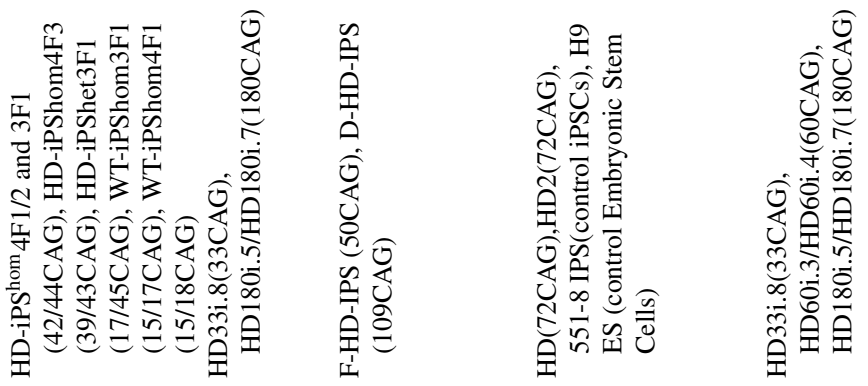

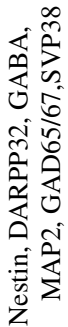

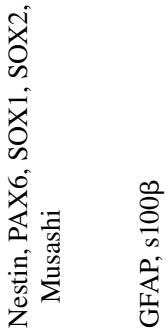
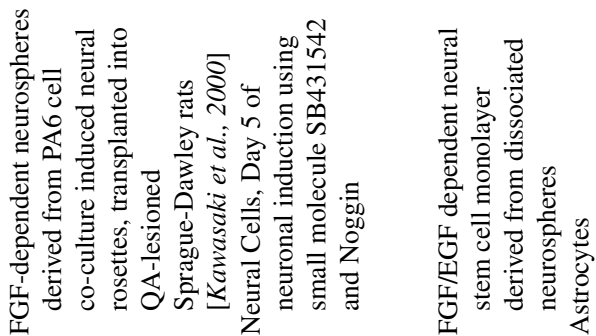

过它离

柁过

政击

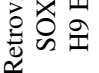
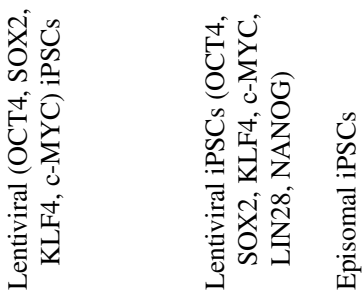

$\stackrel{\check{\Sigma}}{\Sigma}$

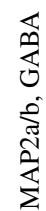
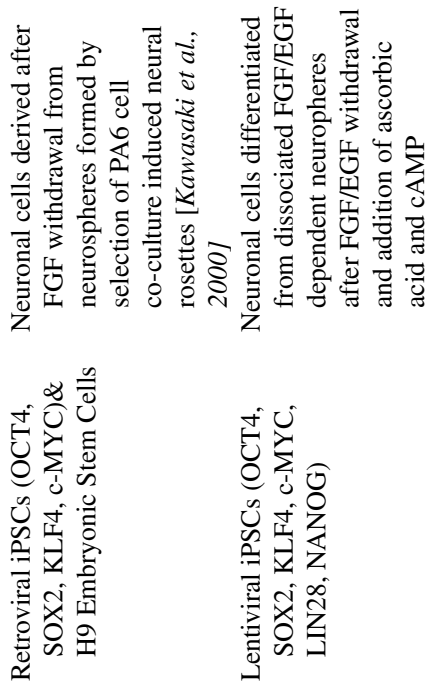


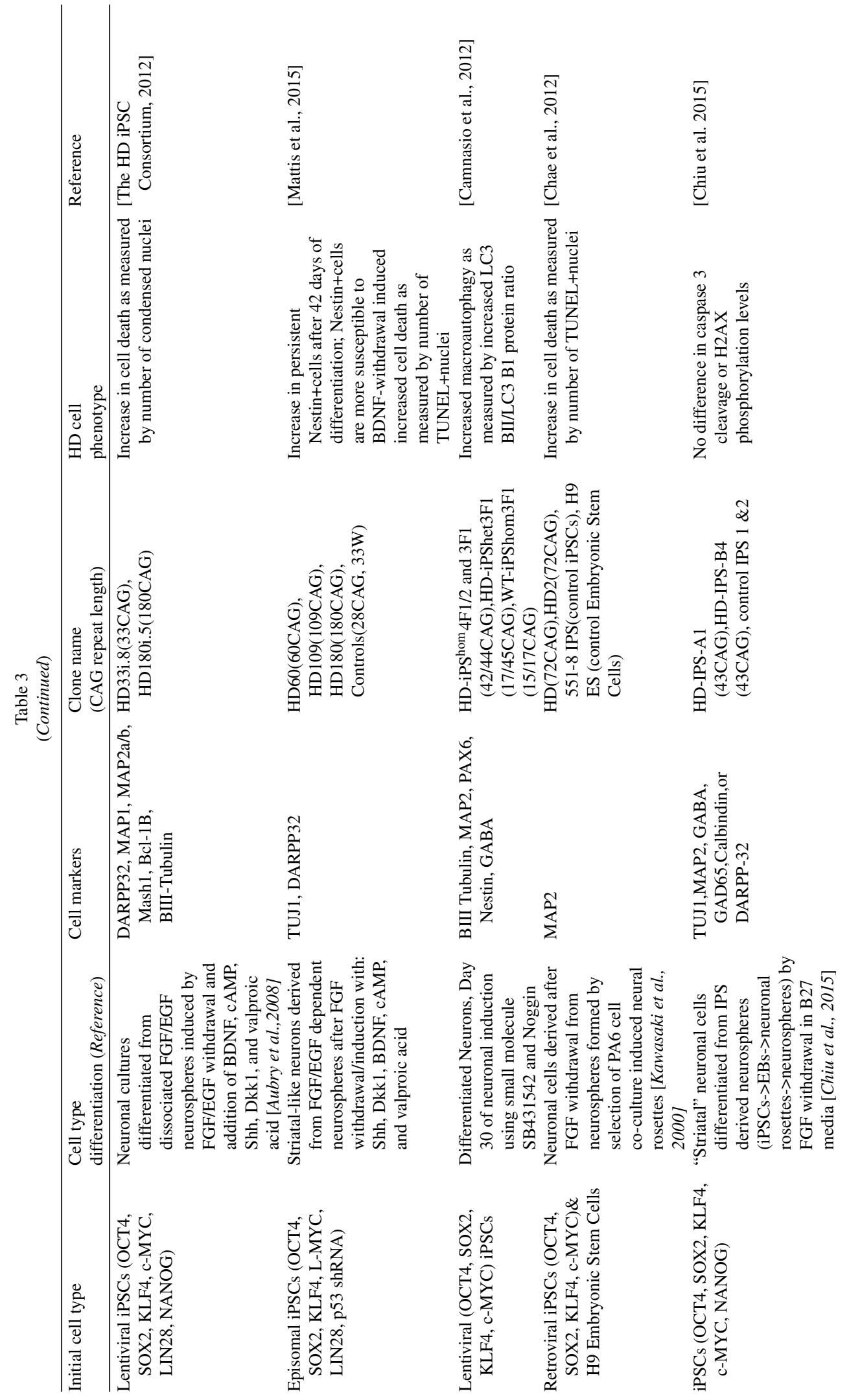



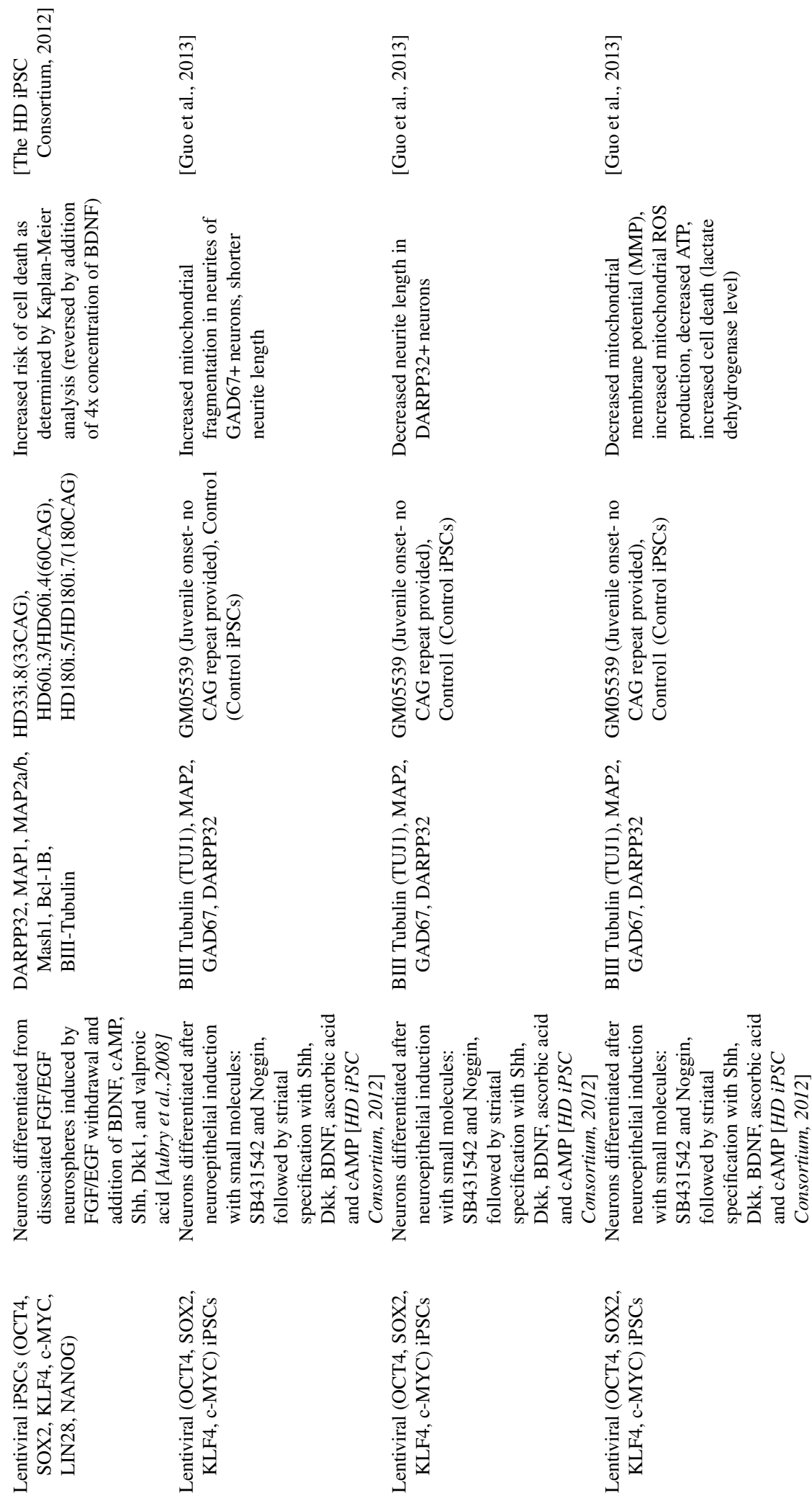


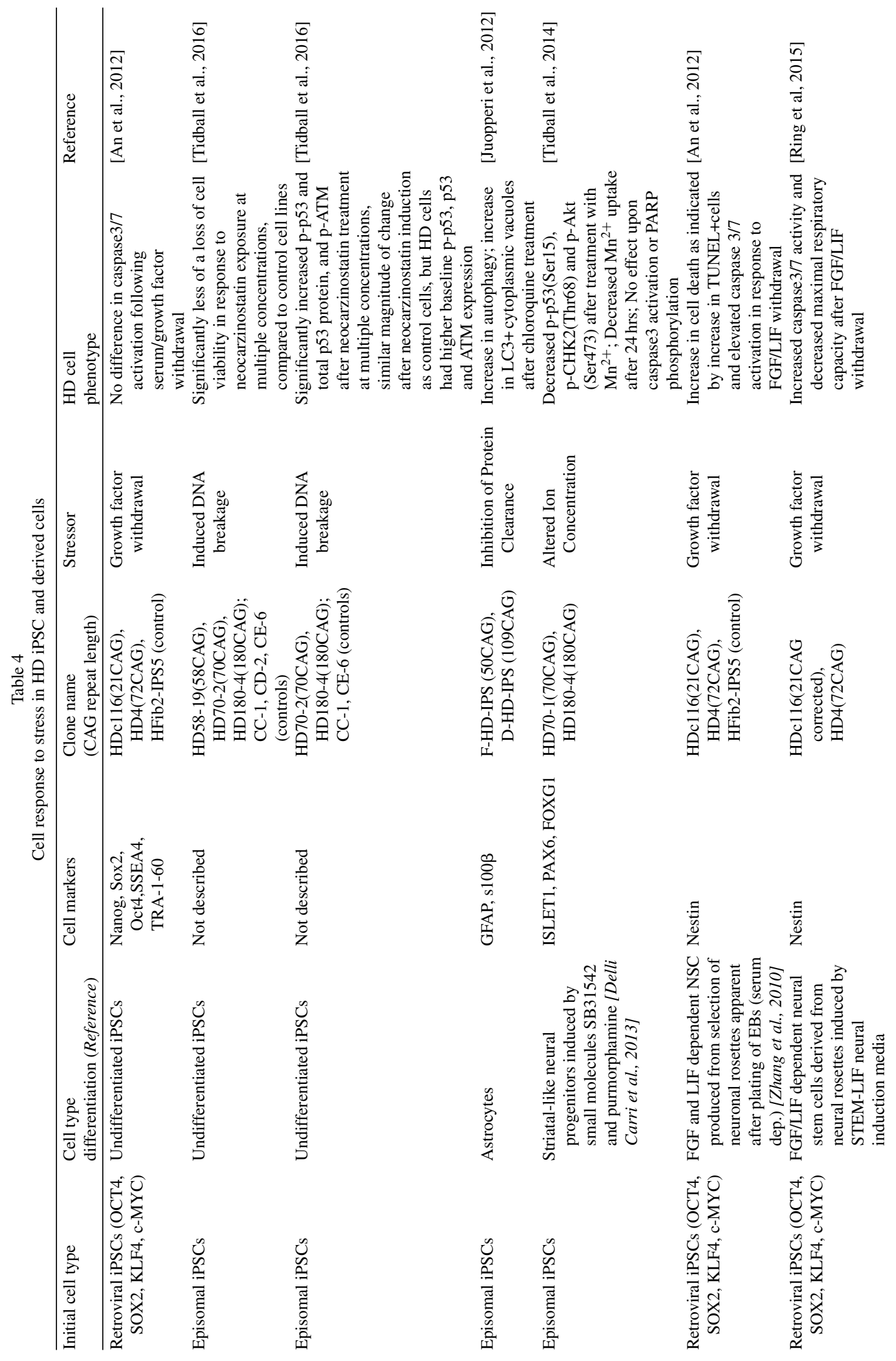




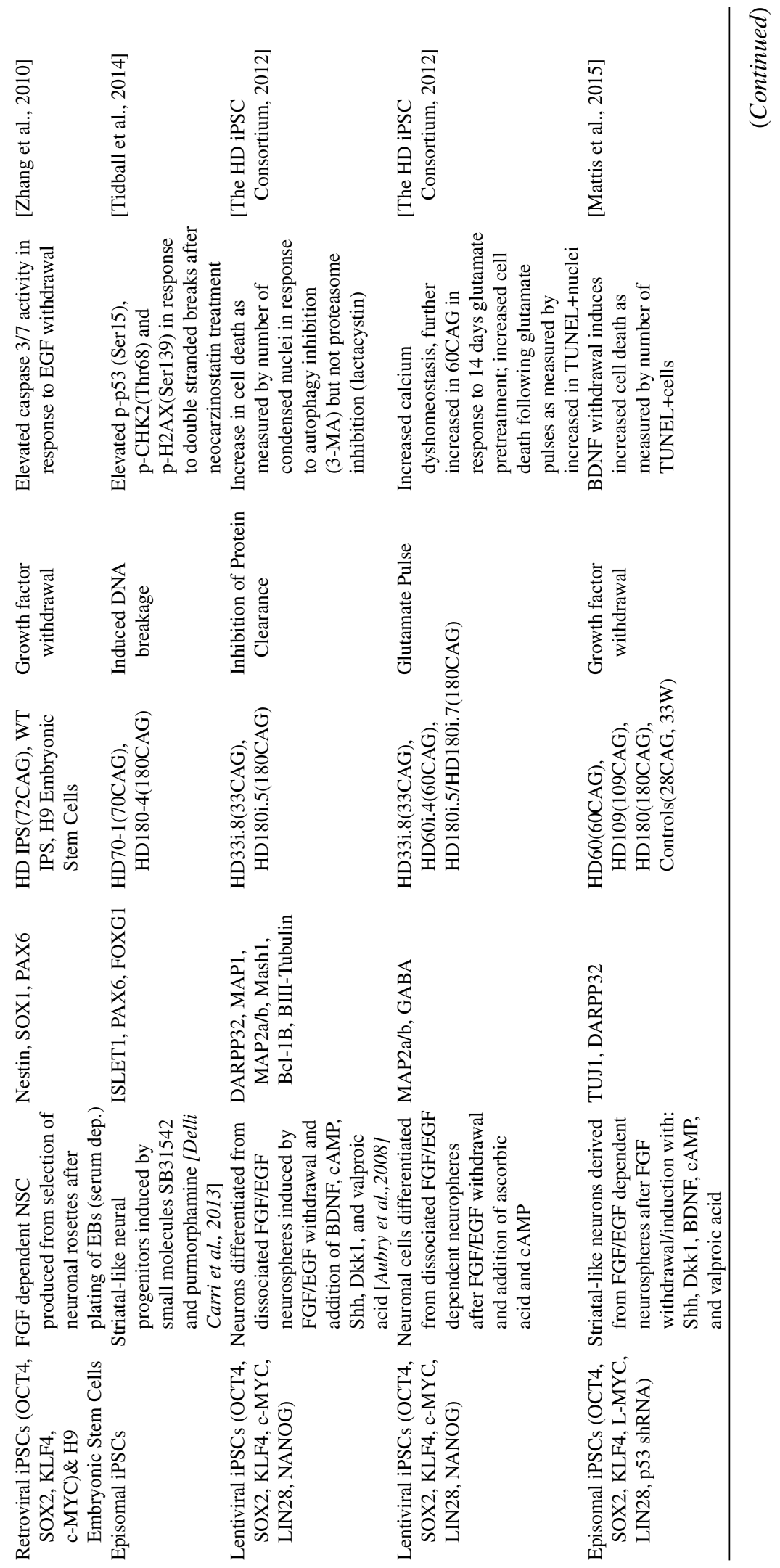




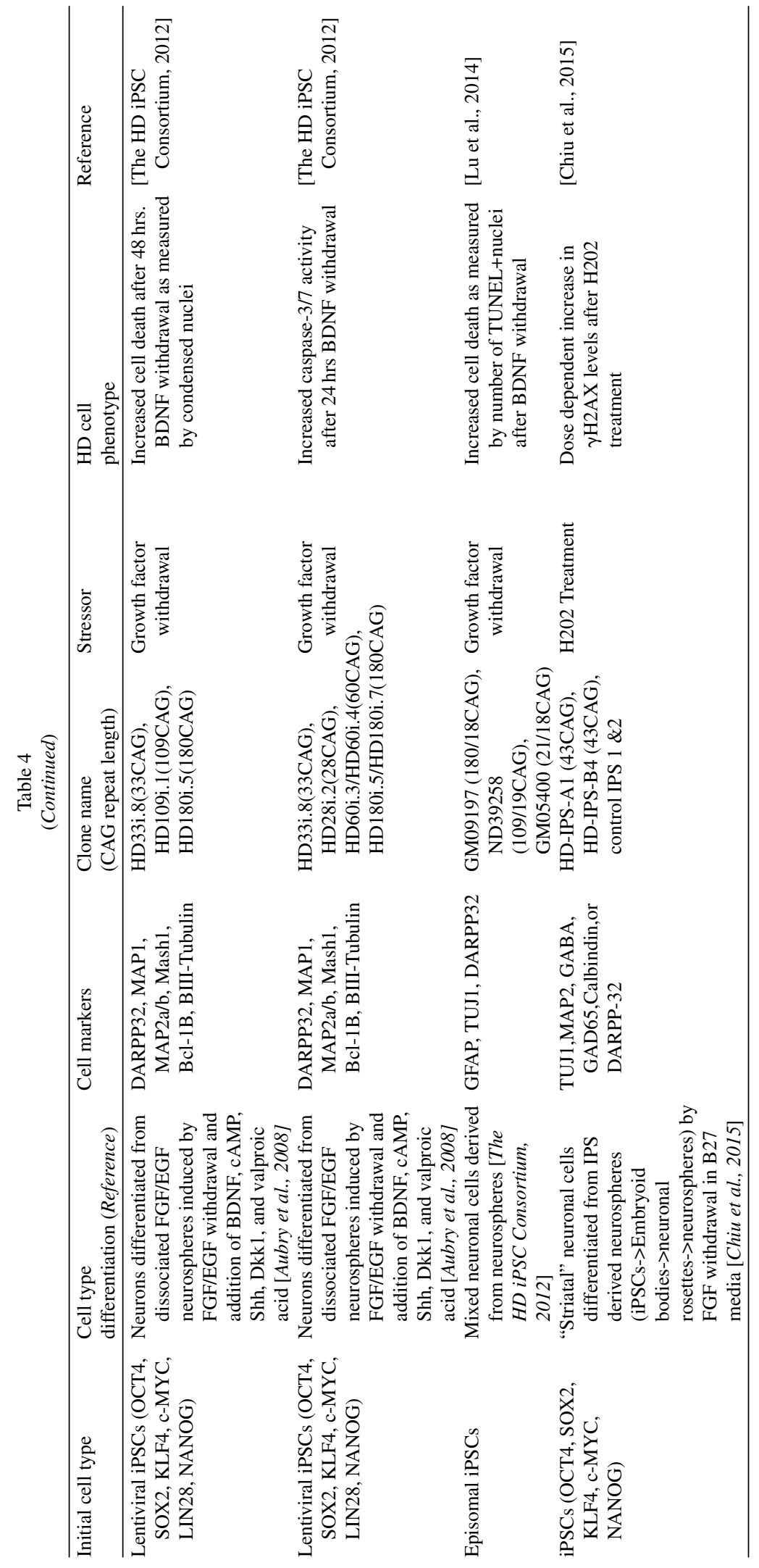


Conclusions about HD iPSC phenotypes have been drawn from a maximum of three HD cell lines compared to one or two control lines in a given publication $[15,16,19,36,41,42]$, with many groups using a single cell line or pair of cell lines compared to controls [14, 17, 18, 20-22, 24, 24-28, 37-40, 43] (see also Tables 1-4 for number of cell lines used in specific studies with their corresponding references). A major problem therefore in phenotype characterization has been the limited efforts to validate results in multiple iPSCs with similar CAG repeats or a range of CAG repeat lengths.

In future studies, one solution to this problem is to use multiple control and HD cell lines. The number of cell lines used should be determined using a power analysis based on data from individual phenotypes, just as in animal studies. Robust phenotypes may require testing far fewer iPSC lines compared to that necessary for more subtle phenotypes. We recommend comparing at least three control and three HD lines lines established from different individuals as an absolute minimum even for robust phenotypes. Subtle phenotypes may require as many as 10-12 cell lines per group and may require HD lines to have very similar CAG repeats. Ideally at least one genetically corrected iPSC paired with its isogenic HD iPSC should also be included, but two corrected clones are preferred to control for off target effects of genome editing. Alternatively, a huntingtin lowering strategy could be used (discussed later in "Maximizing the potential for research with HD iPSCs"). It would also be helpful if researchers currently growing other iPSCs could test published phenotypes in their cells and report conformational studies. Although these types of studies may not be novel and thus may seem of low importance, reproducible HD phenotypes in human cells validated across laboratories is of high value. Several of the current phenotypes have also been shown to occur in animal HD models, increasing confidence that they are real changes that may be important for HD; however, even for changes already shown in other HD models, demonstrating these changes in just one human HD iPSC line is of limited use.

\section{Varied methods create mixed results: comparing apples to apples or apples to oranges?}

Considerable variability exists in the culture methods used to reprogram somatic cells, and to derive NSCs and neurons from HD iPSCs. This limits the ability to draw broad conclusions from the existing published data. Though reprogramming techniques have been consistent: 17 of 24 publications HD cell lines were produced by retroviral or lentiviral reprogramming, the terms 'NSC/NPC' and 'neuron' were used to describe cell populations that varied in a multitude of ways including: protein markers of differentiation, growth factor dependence, and surface matrix [50-54]. The marked differences that exist in culture protocols can be explained to some extent by the ongoing progress made in the iPSC field to improve differentiation efficiency and specificity. Nonetheless, as with iPSCs from patients with other neurodegenerative diseases, the relative homogeneity of cell lines (i.e. few patient donors or few cell lines used during comparisons), when combined with variability in reprogramming and differentiation methods, may disguise subtle but important phenotypes, and make it challenging to determine which phenotypes are disease-relevant rather than due to culture conditions, clonal variation, or genetic background of the patient [55].

There are several protocols for differentiation of iPSCs favoring certain neuronal subtypes including medium spiny neurons (MSNs), the GABA-ergic projection neurons of the striatum that is particularly vulnerable in HD [15, 24, 36, 43, 56-64]. Table 5 summarizes salient features of MSN differentiation protocols. The source of MSNs in the developing human striatum is the lateral geniculate eminence (LGE) of the ventral telencephalon [65, 66]. LGE precursors are characterized by expression of several transcription factors including: GSX2, DLX2, ISL1, BCL11B(CTIP2), FOXP1, and FOXP2 [67]. Mature MSNs are characterized by the co-expression of several protein markers including: DARPP32, BCL11B, FOXP1 or FOXP2 [68, 69].

Driving the differentiation of MSNs from human pluripotent stem cells requires the manipulation of several signaling pathways, including $\mathrm{Wnt} / \beta$-catenin, and Sonic Hedghog (Shh), and bone morphogenic protein (BMP) well described in a recent review by Fjodorova et al. (2015) [70]. The inconsistent and frequently limited efficiency of existing MSN differentiation protocols, ranging from (5-80\% MSN yield, see Table 5) is in part due to the complexity of factors that combine to specify MSN fate. Differentiation of MSNs from iPSC is a lengthy process, with protocols ranging from 3-16 weeks. Production of MSNs from iPSCs requires the derivation of LGE-like neural precursor cells, rather than those approximating the medial or caudal geniculate eminence, the maturation of the neurons rather than maintenance of 


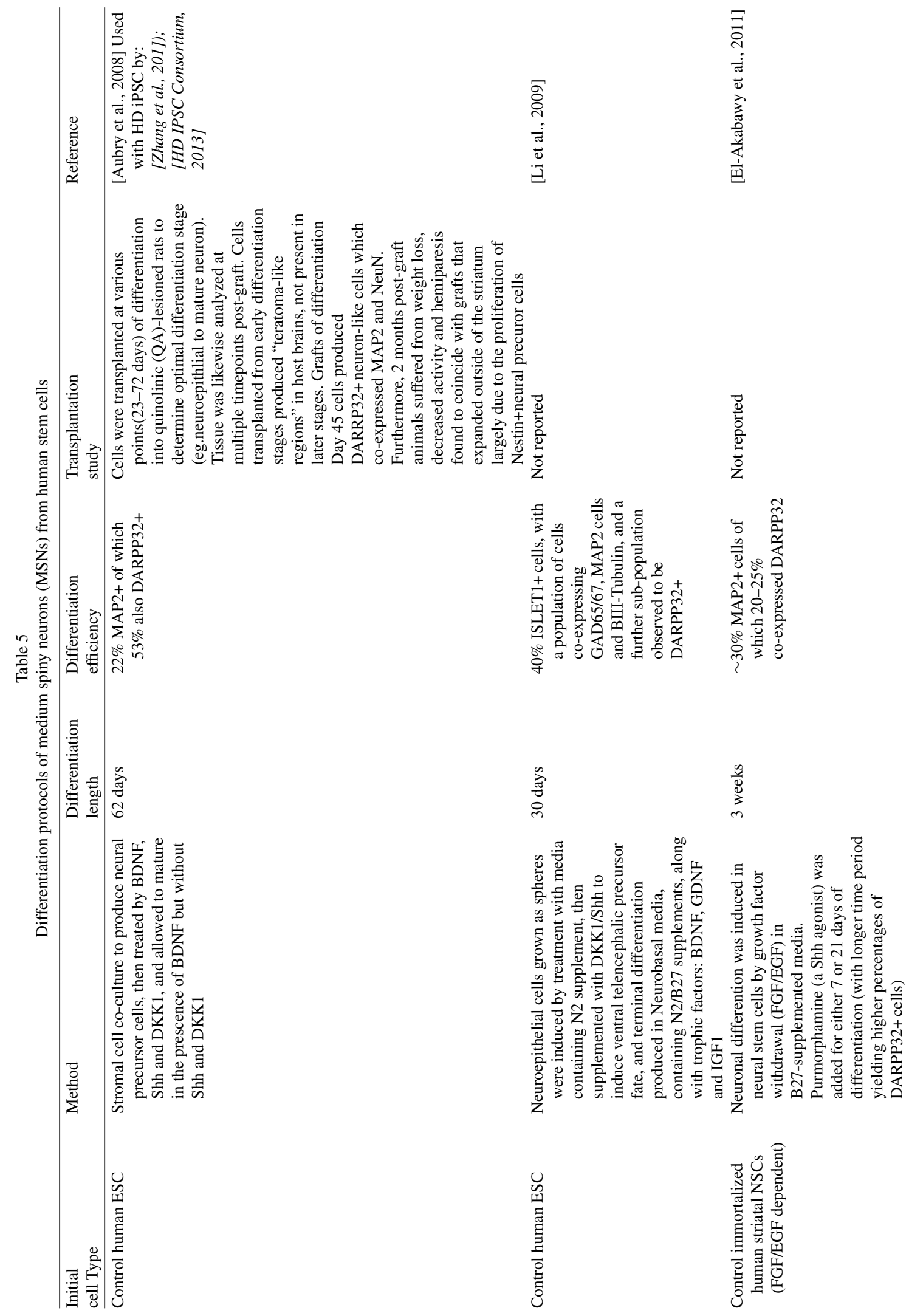




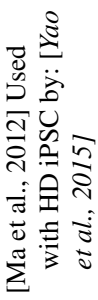

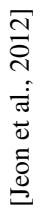

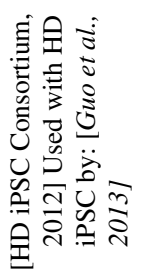

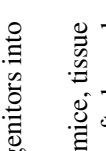

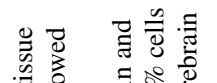

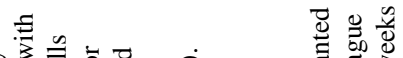

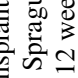

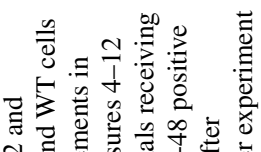

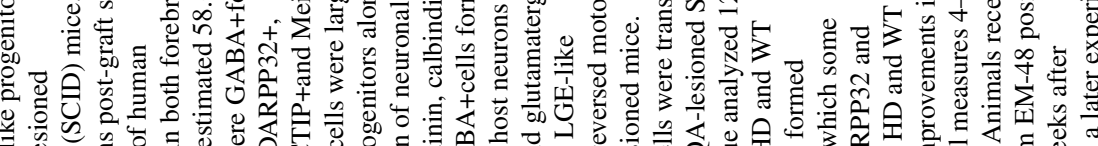

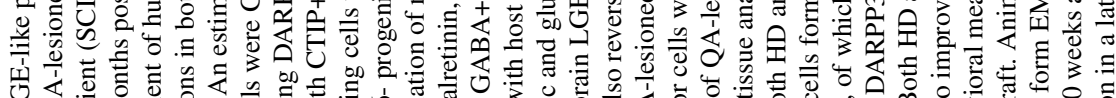

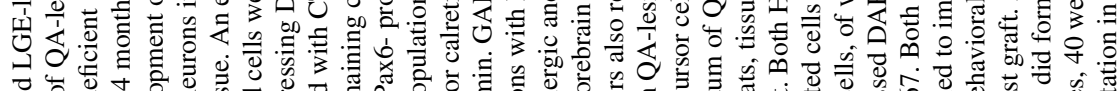

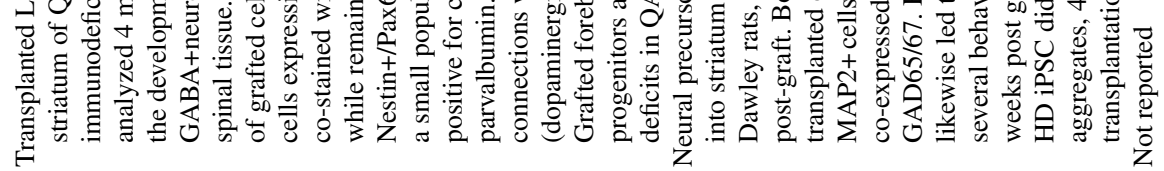
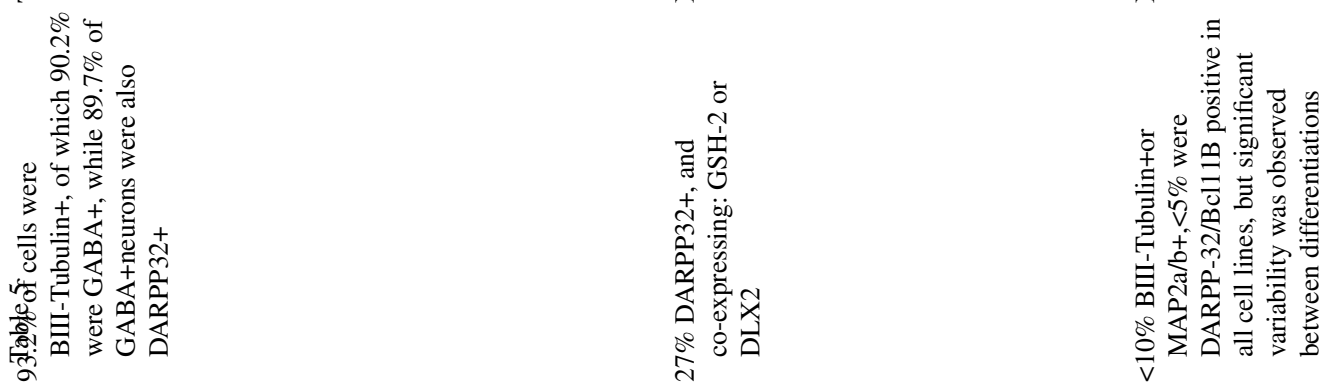

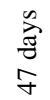

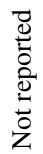

$\sum_{\substack{0\\}}^{N}$

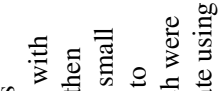

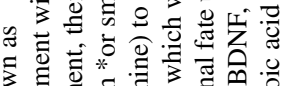

(⿸丆口广

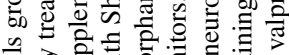

要

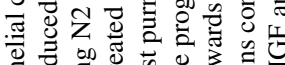

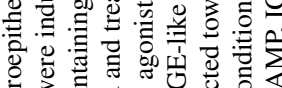

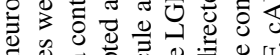

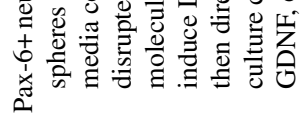

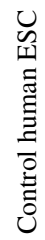

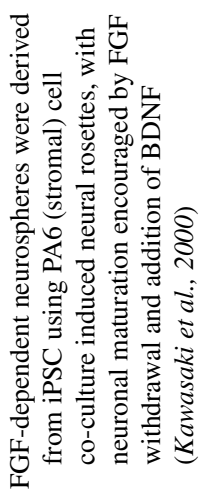

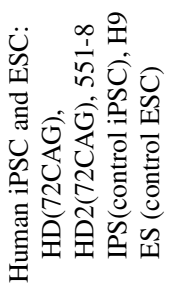

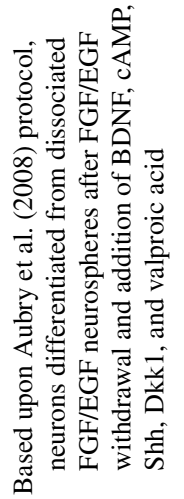

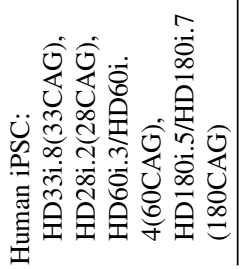




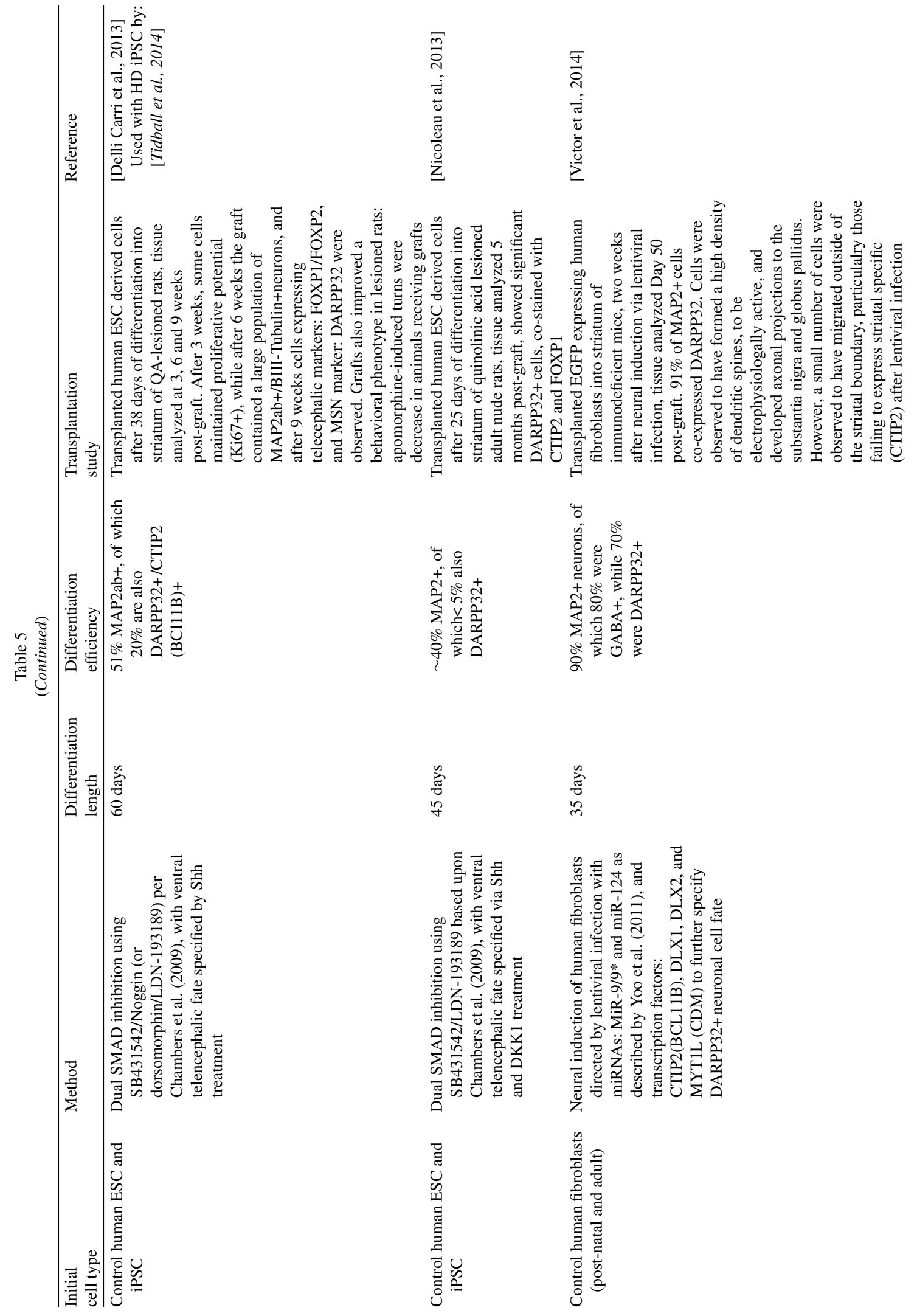




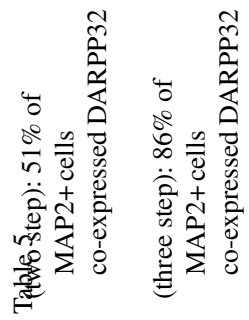

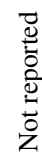

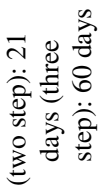

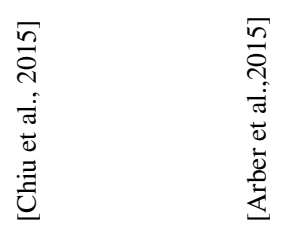

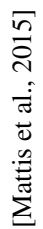

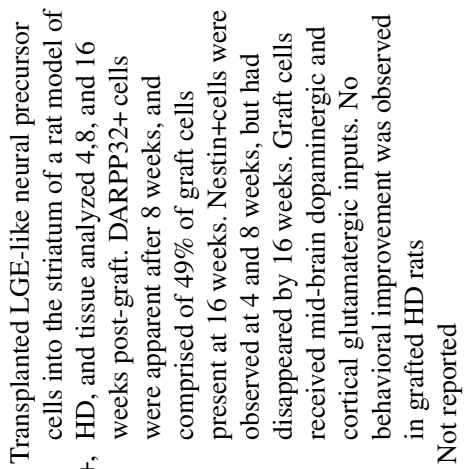

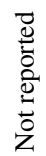

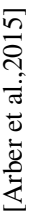

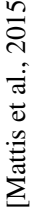

范
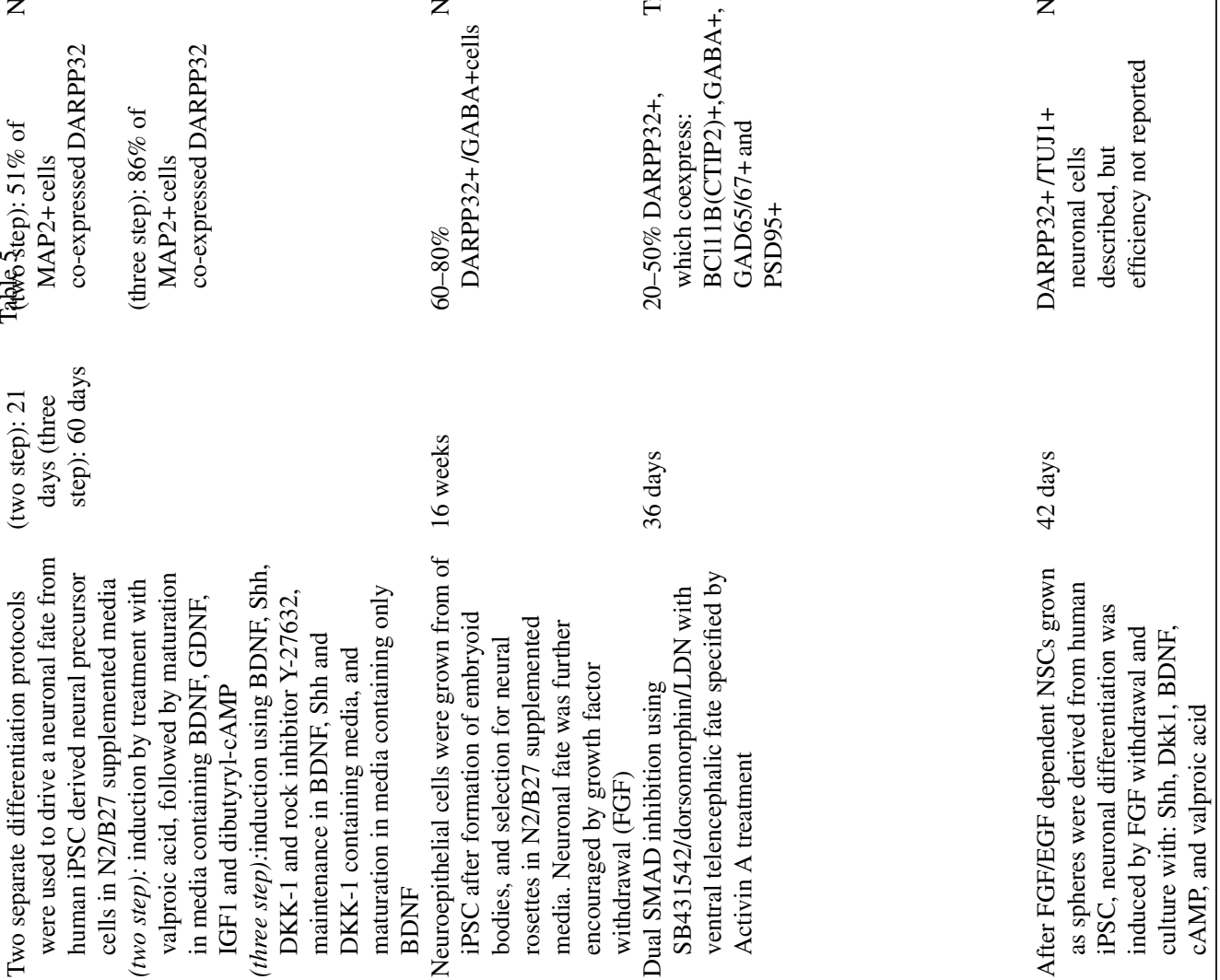

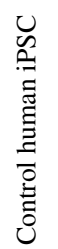
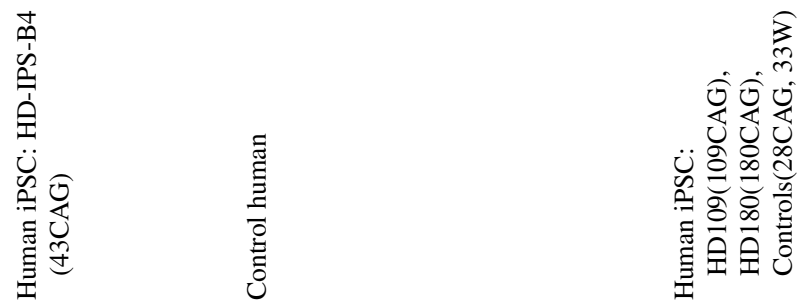
multipotent neural precursor cells or development of glia, and finally the designation of MSNs rather than the olfactory bulb interneurons [65].

The general pattern used in the currently available MSN differentiation protocols includes neural induction using stromal cell co-culture $[24,56]$, exposure to growth factors to induce embryoid body/neural rosette formation $[15,36,43,58,60$, 71], or dual-SMAD/BMP inhibition [62]. Neural induction is followed by specification of LGE precuror/MSN fate using a combination of factors including Shh and DKK1 (a WNT-inhibitor) [15, $36,56-58,71,72]$, or more recently Activin A, a TGF $\beta$ signaling protein [62]. Alternatively, a recent protocol describes the efficient direct induction of adult human fibroblasts to DARPP32+ neurons using lentiviral infection with miRNAs: MiR-9/9* and miR-124 as described by Yoo et al. [73] to encourage neuronal differentiation, and expression transcription factors: CTIP2(BCL11B), DLX1, DLX2, and MYT1L (CDM) to specifically encourage MSN fate [61] (Table 5).

MSN differentiation protocols have largely been described in control cell lines [57-64], with only a few attempted using HD iPSC lines [14, 15, 27, 28, 37]. Further study is necessary to understand how individual cell lines, HD or control, will respond to each differentiation protocol.

\section{Drug discovery and the use of stress induced phenotypes}

Drug screens using animal cell models of HD that express endogenous mutant huntingtin (knock-in) or overexpress mutant huntingtin exogenously, as well as those using human cells overexpressing huntingtin, have failed to identify a compound that prevents, slows or reverses disease onset. A well-characterized human neuronal cell model with huntingtin expression from the endogenous gene locus could be a valuable asset in developing a therapeutic. Numerous screens have already been performed using HD iPSC derived cells [14, 19, 20, 25-27, 36-39, 43]. Table 6 describes initial efforts using HD iPSCs and derived neuronal cells as models for drug screening. Interestingly, in contrast with the analysis of gene/protein changes and characterization of disease relevant phenotypes which were mostly performed in NSCs bearing juvenile repeat lengths ( $>60$ CAGs), experimental screens have largely focused on neuronal cultures from HD iPSCs, and have included low repeat cell lines (43-47 CAGs) [14, 19, 20, 25-27,
36-39, 43]. However for each study, testing is often limited to one or two HD iPSC lines, often without a control or corrected cell line for comparison.

Most phenotypic readouts used to test the effectiveness of novel therapies in HD iPSC derived neuronal cells include a stressor such as growth factor withdrawal, oxidative stress, DNA damage, or glutamate toxicity $[14,19,20,25-27,36-39,43]$ (Table 6). The effect of a drug on cell response to cytokine treatment [26], induced DNA breakage [37], proteasome inhibition [25], $\mathrm{H}_{2} \mathrm{O}_{2}$ or $\mathrm{Mn}^{2+}$ treatment [37, 43] and growth factor withdrawal $[27,36,38,39]$, have been investigated. The TNF $\alpha$ inhibitor XPro-1595 lowered cytokine (TNF $\alpha$ and IL $\beta$ ) induced apoptosis activation and iNOS levels in astrocytes and neurons, respectively, differentiated from iPSCs with 43 CAGs [26]. Adenosine receptor 2A agonists CGS-21680 and APEC produced a dose dependent reduction of oxidative stress toxicity induced by exposure to $\mathrm{H}_{2} \mathrm{O}_{2}$ in $43 \mathrm{CAG}$ neuronal cultures, as measured by decreased $\gamma \mathrm{H} 2 \mathrm{AX}$ induction and caspase 3 cleavage [43]. The microRNA 196a (miR196a) was identified as a candidate that might impact HD using microarray data from transgenic HD monkey tissue; miR196a was found to decrease MG-132 induced EM-48 positive huntingtin aggregates in neuronal cultures differentiated from HD iPSCs with 72 CAGs through an unknown mechanism [25]. An ATM (ataxia-telangiectasia mutated) protein inhibitor KU55933 reversed both neocarzinostatin (a DNA damaging agent) induced increases in phosphorylation of p53, CHK2 and $\gamma \mathrm{H} 2 \mathrm{AX}$, and $\mathrm{Mn}^{2+}$ decreases in p53 phosphorylation in 70 and 180 CAG "striatal-like" NPCs [37].

Several groups have tested drug effects of growth factor (BDNF or FGF/LIF) withdrawal on cell survival [19, 27, 36, 38, 39]. Although cells were grown in medium containing essential nutrients, acute withdrawal of neurotrophins might also be considered a stress once cells have become dependent upon them. Lu et al. (2014) showed that an alternate ATM protein inhibitor, KU60019, reduced BDNF withdrawal-induced increases in TUNEL-positive nuclei and caspase 3 activation in 109 and 180 CAG mixed neuronal cell cultures [38]. Furthermore, to elucidate mechanisms of BDNF-withdrawal induced cell death in neuronal cultures differentiated from HD iPSCs with 109 and 180 CAG, Mattis et al. (2015) showed reversal of increased TUNEL+nuclei after BDNF withdrawal using several compounds including a calcium chelator (BAPTA), TRKB antibody agonist $(\alpha \operatorname{TrkB})$, MAPK signaling inhibitor 


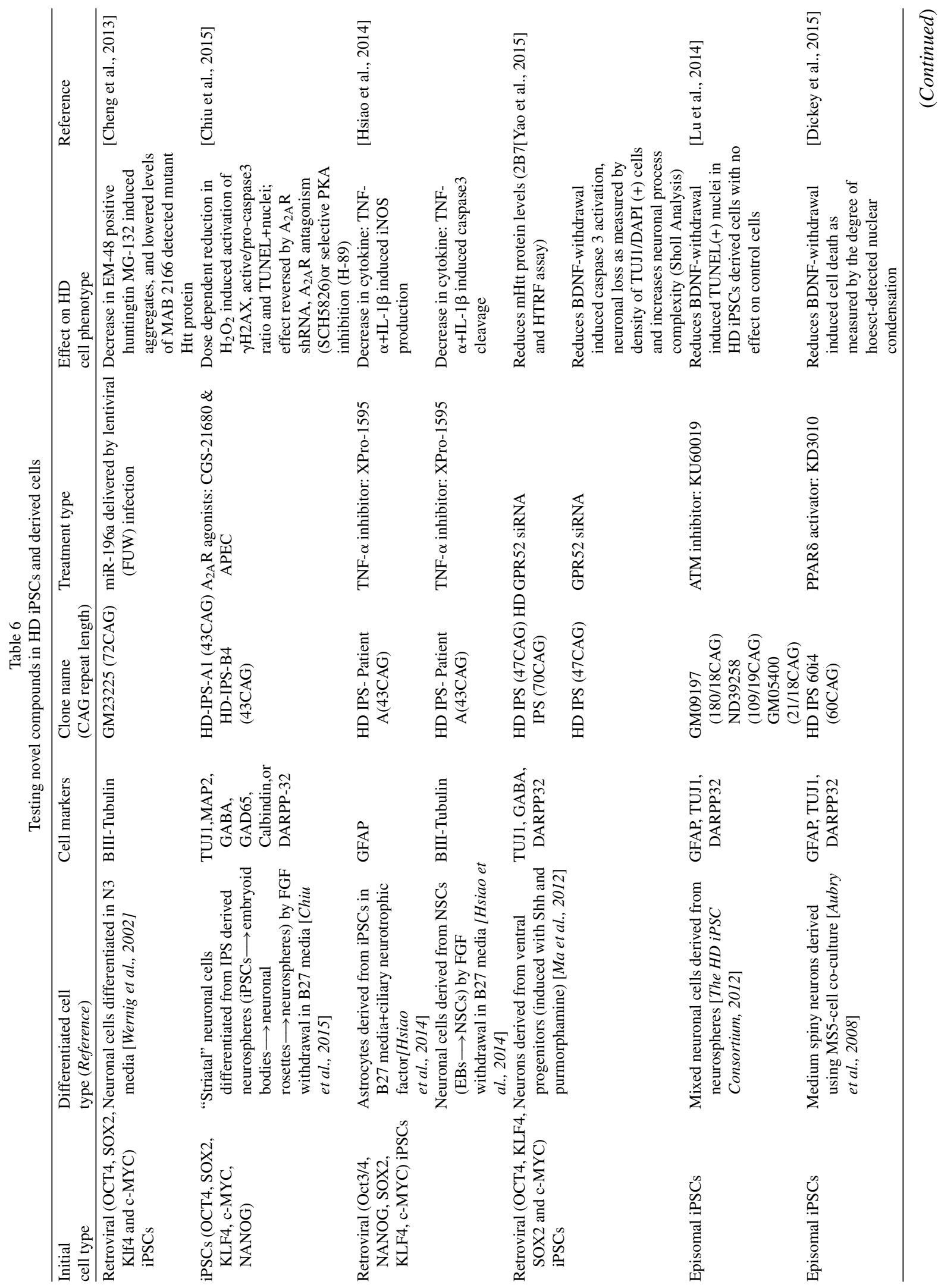




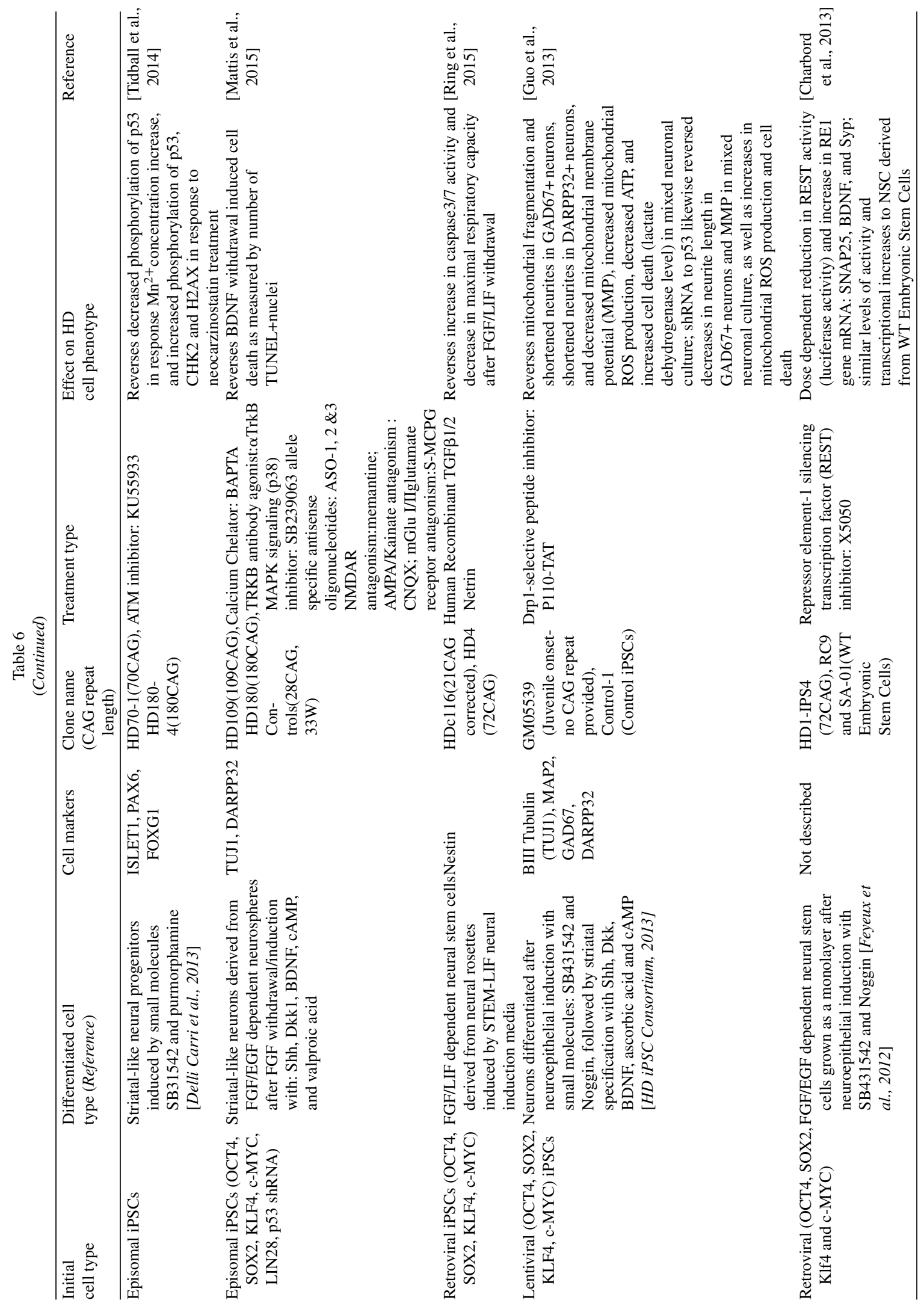


(SB2390463), NMDAR antagonist (memantine) and AMPA/Kainate antagonist (CNQX), and allele specific antisense-oligonucleotides of mutant huntingtin (ASO1, ASO2, ASO3) [36]. Importantly, the susceptible population in the neuronal culture was Nestin+ radial glia-like cells, not neurons.

Likewise, Yao et al. (2015) explored the potential role of G-protein coupled receptor 52 (GPR52) in mediating mutant huntingtin protein toxicity. They found that siRNA knockdown of GPR52 both reduced mutant huntingtin protein levels, and BDNF withdrawal induced caspase 3 activation in HD iPSC derived neurons with 47 and 70 CAG repeats [27]. In addition, Dickey et al. (2016) described the ability of a PPAR $\delta$ activator (KD3010) to reduce numbers of condensed nuclei after BDNF withdrawal from 60 CAG derived neuronal cultures [39]. Finally, Ring et al. (2015) assessed the ability of recombinant TGF $\beta 1 / T G F \beta 2$ and netrin- 1 to reverse increases in caspase $3 / 7$ activity and decreases in maximum respiratory capacity that occur after FGF/LIF withdrawal in NSCs with 72 CAGs; TGF $31 / T G F \beta 2$ treatment was likewise found to be beneficial to HD NSCs under unstressed conditions [19].

Aside from the TGF $\beta$ experiment by Ring et al. [19], only two other groups have tested the effects of a compound on iPSC phenotypes without the addition of a stressor. Charbord et al. (2013) demonstrated that treatment of 72 CAG NSCs with a Repressor element1 silencing transcription factor (REST) inhibitor X5050 produced increased RE1 gene expression and reduced REST activity when compared to control ESC derived NSCs [20]. Guo et al. (2013) showed that a Drp1-selective peptide inhibitor, P110-TAT, reversed: neurite shortening, decreases in mitochondrial membrane potential and ATP level, increases in cell death, mitochondrial fragmentation, and mitochondrial reactive oxygen species (ROS) in mixed neuronal cultures derived from iPSCs derived from juvenile HD patient fibroblasts of unreported CAG length (GM05539, Coriell Cell Repository) [14].

In other disease fields, additional phenotypes have been identified using alternative methods of aging iPSC derived neurons well described in a recent review by Studer et al. (2015) [74]. Recently, exogenous expression of progerin, a mutated form of the nuclear envelope protein lamin A associated with disorder of premature aging, has been used to mimic aging [75]. Overexpression of progerin in iPSC derived dopaminergic neurons resulted in elevated levels of reactive oxygen species (ROS) and DNA damage consistent with the neuronal aging [75].
The same experimental procedure was also used in iPSC derived dopaminergic neurons from Parkinson disease (PD) patients bearing PINK1 and Parkin mutations, and expression of progerin unveiled a decrease in dendrite length specific to PD patient neurons, not identified in progerin-negative cells [75]. The introduction of progerin, along with continued work to understand the molecular mechanisms underlying normal aging could lead to an improved understanding of HD neurodegeneration and future cell models for drug screening. Care should be used with interpretation of results identified using progerin overexpression, however, since cells will be burdened with two mutant proteins, one of which is overexpressed. Furthermore, iPSCs from patients with Hutchinson-Gilford progeria syndrome (HGPS) and atypical Werner syndrome (AWS) which contain mutations in their endogenous LMA gene, have dysmorphic nuclei and premature senescence [76].

\section{Phenotypes relating to disease mechanism}

It is possible that aging and stress might compound or enhance secondary effects of mutant huntingtin but not affect primary drivers of HD progression. If the underlying primary problem causing disease in humans HD is not related to stress or aging, then screening for compounds that reverse stress induced cell death or age related morphology changes may be insufficient to identify novel therapeutics for HD that target crucial changes. Assessing the ability of a given therapeutic to reverse additional alterations such as cell morphology, cell signaling activity or gene expression in the absence of stress may allow for more confident conclusions about drug efficacy [77]. Additional phenotypes useful for screening could include any of the number of disease relevant phenotypes already identified in HD iPSC derived NSC/NPCs and neurons, though further work is necessary to determine the extent to which these phenotypes can be generalized using HD iPSC lines derived from a larger patient population (Tables $3 \& 4$ ).

Utilizing HD iPSCs as a model for early CNS development in HD patients, and determining phenotypes that precede neuronal death may be an equally important and a more readily attainable goal. Study of rodent and human cell models indicate the influence of mutant huntingtin on neural development in general, and specifically related to: premature onset of neural differentiation [78], altered Notch signaling [78] and aberrant mitotic spindle orientation [79, 80]. Recent work has indicated alterations to HD 
patient brains years before symptom onset, including: basal ganglia cell death [81], altered striatal/cortical volume and morphology [81, 82-84], cortico-striatal connectivity $[85,86]$, decreased cortical inhibition [87], and increased oligodendrocyte number [88, 89]. Early cognitive changes have likewise been identified in HD patients related to altered cortico-striatal circuitry [90]. Behavioral changes and altered synaptic connectivity, preceding the onset of motor symptoms, have also been identified in transgenic mouse models of HD [91-94].These findings have encouraged the hypothesis that the huntingtin mutation may alter molecular pathways, cell phenotypes and activity during neural development, and the cumulative effects of these changes over time eventually lead to disease onset well described in several reviews: [50, $88,95,96]$.

Genomic and proteomic analyses of HD iPSC and derived neuronal cells support the importance of continued exploration of the role of mutant huntingtin in disrupting the normal differentiation and maturation of human cells. Differentiation of HD iPSCs to NSCs and neurons has uncovered differences in the efficiency [18] and composition of cultures [36], when compared to iPSCs from healthy controls. Furthermore, comparisons of gene microarray and RNAseq data between HD4 (72 CAGs) HD iPSCs and a cell line corrected to $21 \mathrm{CAGs}$ identified axonal guidance [19] and cadherin, TGF $\beta$ and SMAD3 signaling [17, 19] as pathways significantly altered in HD cells. Altered expression of genes specifically related to striatal development were also identified in the same cells [19].

Other brain cell types may contribute to HD pathology. Changes to astrocytes, microglia, and oligodendrocytes have been observed in both HD patients [89, 97-101], and transgenic animal models of HD [101-108]. Several protocols have been shown to produce astrocytes [109-114] and oligodendrocytes [115-118] from human iPSCs (45). Two groups have used HD iPSCs to produce GFAP+astrocytes [26, 40] (Tables 3 \& 6). Juopperi et al. (2012) reported a CAG-repeat dependent increase in cytoplasmic vacuolization in HD astrocytes derived from $50 \mathrm{CAG}$ and $109 \mathrm{CAG}$ iPSC lines, and related the change to a potential alteration in autophagy as overnight treatment with chloroquine, an autophagy inhibitor, increased LC3+ positive vacuoles in HD cells [40]. Hsiao et al. (2014) showed that a TNF$\alpha$ inhibitor, XPro-1595, lowers cytokine (TNF- $\alpha$ \& IL- $\beta$ ) induced iNOS production in astrocytes derived from iPSCs with 43 CAGs [26]. So far, no work has been published describing HD iPSC derived oligodendrocytes. Further exploration of HD iPSC derived glia, along with co-culture of iPSC derived neurons and glia, may shed light on sources of non-cell autonomous toxicity in HD pathogenesis.

\section{Technical caveats that may undermine phenotype characterization}

Despite their advantages, unanswered questions about iPSC as a model remain. One area of particular interest for investigating age-related diseases such as HD is obliteration of age from the patient sample. Several studies indicate that induced pluripotency reverses typical age-related phenotypes, such as telomere shortening [119-121] and mitochondrial dysfunction [74, 121, 122]. A total reversal of age related changes such as alterations in levels of oxidative stress, DNA packaging and damage, nuclear morphology and related gene expression changes occurred in fibroblasts differentiated from iPSCs that had been collected from donor patients in different age ranges [74]. Transdifferentiation or directed differentiation to neurons from aged fibroblasts may be one approach to maintaining age $[4,61,77]$. Another issue is the potential for reprogrammed cells to bear an 'epigenetic memory' of their somatic cell source [4, 74, 123-125]. A recent study by Kim et al. (2011) indicated that iPSCs retain some residual DNA methylation from their parental cell type (fibroblast or blood cell), rending them more readily differentiated to their parent cell's fate [124]. However, recent work also suggests that repeated passaging [126] or chromatin modifying agents [127] can diminish or fully reset this 'epigenetic memory' [124].

The extent to which the phenomenon of epigenetic memory and limited pluripotency may affect neuronal cells derived from of HD iPSCs is as yet, uncertain. Reprogramming, continuous passage (cell dissociation and re-culturing) to high passage number, and differentiation of iPSCs have been shown to lead to genetic instability [128-132]. Investigators using iPSCs are thus cautioned when using highly passage cells. Encouraging results showed few changes in human iPSCs due to mutant huntingtin. The HD iPSC Consortium (2013) reported an expansion from 110 to 118 CAGs in one HD iPSC derived NSC line, but no changes in iPSC karyotype [15]. Camnasio et al. (2012) reported occasional changes in karyotype in both control and HD iPSCs but stable CAG repeat lengths [16]. This is in contrast to 
NSCs established from embryonic brain tissue from homozygous CAG140 knock-in mice which became tetraploid after very few passages in culture [133]. However, a recent finding by Tidball et al. (2016) showed increased somatic instability in HD iPSCs using siRNA targeting p53 to increase the efficiency of reprogramming [42]. Further study is necessary to determine the extent to which additional changes occur in human HD iPSC lines and differentiated cells, but so far the CAG repeat expansion and presence of mutant huntingtin protein do not seem to impose genetic instability.

While progress towards understanding HD mechanisms using iPSC has been unquestionably substantial, there are challenges in drawing broad conclusions about disease pathogenesis from these studies. Limitations on the number of HD and control cell lines used are understandable considering the cost and effort in maintaining human stem cells. However, given the relatively small number of cell lines studied, care should be taken when interpreting results. Although HD is caused by just one gene, the patient donors have diverse genetic backgrounds that could account for many of the changes observed. As with any experiment, sample size increases confidence in results. Efforts should be supported for additional testing of existing cell lines and for continued creation of new cell lines to overcome this limitation. Furthermore, determining the presence of certain phenotypes and susceptibility to specific treatments one day may be possible using iPSC derived neurons allowing for tailored treatments (so called "personalized medicine") [134]. The availability of cell lines from diverse genetic backgrounds is critical for these efforts.

\section{Maximizing the potential for research with $H D$ iPSCs}

Genetic correction to create non-disease CAG repeat lengths in iPSCs with the same genetic background as diseased cells in theory removes at least one confounding variable thereby diminishing barriers to identifying less subtle phenotypes. An et al. (2012) reported the successful use of homologous recombination to correct the $72 \mathrm{CAG}$ allele of an HD4 iPSC line to 21 CAG [17]. Recent advances in gene editing technology should make genetic correction of iPSC easier [50-52, 77, 135-138]. The potential for zinc finger nucleases (ZFNs), transcription activatorlike effector nucleases (TALENS), and clustered regularly-interspaced short palindromic repeats/Cas
9 (CRISPR/Cas9) to modify human stem cells has been well described $[4,55,138]$. Each method bears limitations in the targeting of guiding DNA/RNA sequences, as well as differing propensities for offtarget effects [55, 138], although off target effects are reduced in pluripotent stem cells in contrast to other cells [139]. Current methods of gene editing rely on endogenous machinery to repair DNA breaks produced by an exogenous nuclease (i.e., CRISPR or Fok1) $[4,135,138]$. Several recent findings indicate that the molecular pathways underlying DNA repair may be altered or aberrantly active in HD iPSCs [18, 37, 38, 42, 43], consistent with somatic CAG repeat expansions in post-mortem brain tissue from HD patients, and oxidative DNA damage in HD animal models [140]. These existing changes in HD cells could have adverse effects on the efficiency of genetic corrections, and susceptibility of cells to off-target effects. There are ongoing efforts to target single nucleotide polymorphisms (SNPs) specific to the mutated HD allele and to contract the expanded CAG repeat in heterozygous cell lines [53] in order to create a series of iPSC lines with different $\mathrm{CAG}$ expansions lengths on the same genetic background to determine CAG repeat length dependent phenotypes. An HD allelic series 21, 72 and 97 CAGs, was successfully created by An et al., (2014) using the CRISPR/Cas9 gene editing system [44]. One practical problem is that unfortunately many of the existing iPSC lines are not heterozygous for SNPs that could be targeted by CRISPR/Cas9 making allele-specific changes difficult in these lines (our unpublished observations).

Just as an 'epigenetic memory' of the somatic cell source may persist in iPSCs after reprogramming, it is as yet unknown if contracting expanded CAG repeats in HD iPSCs will fully reverse the effects of the HD mutation on derived neuronal cells. Using a genetic correction as the control will obscure phenotypes that cannot be reversed since both the mutant and the isogenic corrected line will continue to share the condition; thus they will not be observed as "different". Analysis of gene and protein expression and epigenetic modifications, comparing both HD iPSC line and iPSC lines derived from healthy patient controls is necessary to understand the extent to which genetic correction in HD iPSC lines can reverse HD phenotypes; it is possible that some phenotypes can be reversed in one cell line with a particular genetic background, but not in another (for in-depth coverage of this topic please see [141]). For HD, only one iPSC (HD4) has been subjected to correction. Correction 
by homologous recombination of the iPSC line HD4 from 72 CAGs to 21 CAGs reversed phenotypes of altered TGF-beta and cadherin gene expression [17] and changes to gene ontology categories including synaptic assembly, axonal guidance and SMAD3 signaling [19]. Far fewer changes were found between HD4 and the corrected line, versus HD4 and an unrelated control iPSC line, supporting the notion that an isogenic background is a good control. Studies comparing iPSC derived neurons from healthy controls to Parkinson patients bearing mutations in LRRK2 gene demonstrated that gene expression cluster profiles did not partition with the mutation, indicating the normal genomic variability had a stronger effect than the mutation [142]; meaningful changes were only found using an isogenic corrected control. Additional studies comparing phenotypes of HD4 and the corrected cell line with numerous control cell lines will be informative. These issues are particularly important in considering the potential of genetically corrected HD iPSCs as a tissue source for cell replacement therapy $[45,52,53,123]$.

As an alternative to genetic editing, levels of mutant protein can be lowered using methods that specifically target mutant huntingtin RNA stability and protein expression including: anti-sense oligonucleotides (ASOs), small interfering RNA (siRNA), short hairpin RNA (shRNA) [53], and microRNAs (miRs). Mattis et al. 2015 reported the ability of allele-specific ASOs to lower levels of mutant huntingtin expression and reverse BDNF-withdrawal induced toxicity in 109 and 180 CAG HD iPSC derived neurons [36]. As mentioned above, many existing iPSC lines are homozygous at SNPs that could be used for allele-specific targeting by known useful siRNAs, shRNAs, and miRs making allele specific knockdown of mutant huntingtin difficult or impossible using these methods. Zinc finger proteins (ZFPs) are also being developed (by Sangamo) to repress transcription of the HTT allele bearing expanded CAGs and thus specifically reduced mutant huntingtin protein levels.

\section{CONCLUSIONS}

Significant progress has been made in the HD iPSC field. Now that numerous HD iPSCs are available to researchers, individual studies should be performed using as many cell lines as appropriate based on a power analysis for individual phenotypes. The limited number of studies on iPSCs and their differentiated progeny using lines with adult onset CAG lengths is concerning since adult onset HD represents the vast majority of HD cases. Work with HD embryonic stem (ES) cells has focused on lower repeat lengths (37-51 CAG) [49, 143-145]. However, use of HD ES cells abrogates the ability to correlate cellular phenotypes with patient symptoms, a major effort underway in other neurodegenerative diseases using iPSC models [134]. Renewed efforts should be undertaken to continue to increase the repertoire of available stem cell lines as existing lines age with passage. Further investigations should be directed toward identifying phenotypes in HD iPSCs bearing an expanded allele in the adult onset range and investigating changes that occur in the absence of exogenous stress. New methods using 3-dimensional culture or co-culture systems may be key to unveiling phenotypes in the absence of stress. Finally, it would be helpful if the field as a whole would settle on one or two differentiation schemes to improve comparison among studies. Thanks to the pioneering work of numerous HD investigators, HD iPSCs are just beginning to show their promise and may be the key to finally identifying treatments useful in HD patients.

\section{ACKNOWLEDGMENTS}

We thank Marian DiFiglia for invaluable help editing the manuscript. KKG is funded by CHDI.

\section{CONFLICT OF INTERESTS}

The authors have no conflicts to declare.

\section{REFERENCES}

[1] Takahashi K, Yamanaka S. Induction of pluripotent stem cells from mouse embryonic and adult fibroblast cultures by defined factors. Cell. 2006;126:663-76. doi:10.1016/j.cell.2006.07.024

[2] Park I-H, Arora N, Huo H, Maherali N, Ahfeldt $\mathrm{T}$, Shimamura A, et al. Disease-specific induced pluripotent stem (iPS) cells. Cell. 2008;134:877-86. doi:10.1016/j.cell.2008.07.041

[3] Yu J, Vodyanik MA, Smuga-Otto K, Antosiewicz-Bourget J, Frane JL, Tian S, et al. Induced pluripotent stem cell lines derived from human somatic cells. Science. 2007;318:1917-20. doi:10.1126/science.1151526

[4] Qiang L, Fujita R, Abeliovich A. Remodeling neurodegeneration: Somatic cell reprogramming-based models of adult neurological disorders. Neuron. 2013;78:957-69. doi:10.1016/j.neuron.2013.06.002

[5] Loh Y-H, Agarwal S, Park I-H, Urbach A, Huo H, Heffner GC, et al. Generation of induced pluripotent 
stem cells from human blood. Blood. 2009;113:5476-9. doi:10.1182/blood-2009-02-204800

[6] Chou B-K, Mali P, Huang X, Ye Z, Dowey SN, Resar LM, et al. Efficient human iPS cell derivation by a non-integrating plasmid from blood cells with unique epigenetic and gene expression signatures. Cell Res. 2011;21:518-29. doi:10.1038/cr.2011.12

[7] Aasen T, Raya A, Barrero MJ, Garreta E, Consiglio A, Gonzalez F, et al. Efficient and rapid generation of induced pluripotent stem cells from human keratinocytes. Nat Biotechnol. 2008;26:1276-84. doi:10.1038/nbt.1503

[8] Raab S, Klingenstein M, Liebau S, Linta L. A comparative view on human somatic cell sources for iPSC generation. Stem Cells Int. 2014;2014:768391. doi:10.1155/2014/768391

[9] Zhou T, Benda C, Duzinger S, Huang Y, Li X, Li $\mathrm{Y}$, et al. Generation of induced pluripotent stem cells from urine. J Am Soc Nephrol JASN. 2011;22:1221-8. doi:10.1681/ASN.2011010106

[10] Schlaeger TM, Daheron L, Brickler TR, Entwisle S, Chan $\mathrm{K}$, Cianci A, et al. A comparison of non-integrating reprogramming methods. Nat Biotechnol. 2015;33:58-63. doi:10.1038/nbt. 3070

[11] González F, Boué S, Izpisúa Belmonte JC. Methods for making induced pluripotent stem cells: Reprogramming á la carte. Nat Rev Genet. 2011;12:231-42. doi: $10.1038 / \mathrm{nrg} 2937$

[12] Hu K. All roads lead to induced pluripotent stem cells: The technologies of iPSC generation. Stem Cells Dev. 2014;23:1285-300. doi:10.1089/scd.2013.0620

[13] Brouwer M, Zhou H, Kasri NN. Choices for Induction of Pluripotency: Recent Developments in Human Induced Pluripotent Stem Cell Reprogramming Strategies. Stem Cell Rev Rep. 2015;12:54-72. doi:10.1007/s12015-0159622-8

[14] Guo X, Disatnik M-H, Monbureau M, Shamloo M, Mochly-Rosen D, Qi X. Inhibition of mitochondrial fragmentation diminishes Huntington's disease-associated neurodegeneration. J Clin Invest. 2013;123:5371-88. doi:10.1172/JCI70911

[15] The HD iPSC Consortium. Induced pluripotent stem cells from patients with Huntington's disease show CAGrepeat-expansion-associated phenotypes. Cell Stem Cell. 2012;11:264-78. doi:10.1016/j.stem.2012.04.027

[16] Camnasio S, Carri AD, Lombardo A, Grad I, Mariotti C, Castucci A, et al. The first reported generation of several induced pluripotent stem cell lines from homozygous and heterozygous Huntington's disease patients demonstrates mutation related enhanced lysosomal activity. Neurobiol Dis. 2012;46:41-51. doi:10.1016/j.nbd.2011.12.042

[17] An MC, Zhang N, Scott G, Montoro D, Wittkop T, Mooney $\mathrm{S}$, et al. Genetic correction of Huntington's disease phenotypes in induced pluripotent stem cells. Cell Stem Cell. 2012;11:253-63. doi:10.1016/j.stem.2012.04.026

[18] Chae J, Kim D, Lee N, Jeon Y, Jeon I, Kwon J, et al. Quantitative proteomic analysis of induced pluripotent stem cells derived from a human Huntington's disease patient. Biochem J. 2012;446:359-71. doi:10.1042/BJ20111495

[19] Ring KL, An MC, Zhang N, O'Brien RN, Ramos EM, Gao $\mathrm{F}$, et al. Genomic analysis reveals disruption of striatal neuronal development and therapeutic targets in human Huntington's disease neural stem cells. Stem Cell Rep. 2015;5:1023-38. doi:10.1016/j.stemcr.2015.11.005

[20] Charbord J, Poydenot P, Bonnefond C, Feyeux M, Casagrande F, Brinon B, et al. High throughput screen- ing for inhibitors of REST in neural derivatives of human embryonic stem cells reveals a chemical compound that promotes expression of neuronal genes. Stem Cells Dayt Ohio. 2013;31:1816-28. doi:10.1002/stem.1430

[21] Ooi J, Hayden MR, Pouladi MA. Inhibition of excessive monoamine oxidase $\mathrm{A} / \mathrm{B}$ activity protects against stress-induced neuronal death in Huntington disease. Mol Neurobiol. 2015;52:1850-61. doi:10.1007/s12035014-8974-4

[22] Martín-Flores N, Romaní-Aumedes J, Rué L, Canal M, Sanders P, Straccia M, et al. RTP801 is involved in mutant huntingtin-induced cell death. Mol Neurobiol. 2015:1-12. doi:10.1007/s12035-015-9166-6

[23] Jeon I, Choi C, Lee N, Im W, Kim M, Oh S-H, et al. In vivo roles of a patient-derived induced pluripotent stem cell line (HD72-iPSC) in the YAC128 model of Huntington's disease. Int J Stem Cells. 2014;7:43-7. doi:10.15283/ijsc.2014.7.1.43

[24] Jeon I, Lee N, Li J-Y, Park I-H, Park KS, Moon J, et al. Neuronal Properties, in vivo effects, and pathology of a Huntington's disease patient-derived induced pluripotent stem cells. Stem Cells. 2012;30:2054-62. doi:10.1002/stem.1135

[25] Cheng P-H, Li C-L, Chang Y-F, Tsai S-J, Lai Y-Y, Chan AWS, et al. miR-196a ameliorates phenotypes of Huntington disease in cell, transgenic mouse, and induced pluripotent stem cell models. Am J Hum Genet. 2013;93:306-12. doi:10.1016/j.ajhg.2013.05.025

[26] Hsiao H-Y, Chiu F-L, Chen C-M, Wu Y-R, Chen H-M, Chen Y-C, et al. Inhibition of soluble tumor necrosis factor is therapeutic in Huntington's disease. Hum Mol Genet. 2014:ddu151. doi:10.1093/hmg/ddu151

[27] Yao Y, Cui X, Al-Ramahi I, Sun X, Li B, Hou J, et al. A striatal-enriched intronic GPCR modulates huntingtin levels and toxicity. eLife. 2015;4 doi:10.7554/eLife.05449

[28] Zhang N, An MC, Montoro D, Ellerby LM. Characterization of human Huntington's disease cell model from induced pluripotent stem cells. PLoS Curr. 2010;2:RRN1193. doi:10.1371/currents.RRN1193

[29] Ban H, Nishishita N, Fusaki N, Tabata T, Saeki K, Shikamura M, et al. Efficient generation of transgenefree human induced pluripotent stem cells (iPSCs) by temperature-sensitive Sendai virus vectors. Proc Natl Acad Sci U S A. 2011;108:14234-9. doi:10.1073/pnas. 1103509108

[30] Stadtfeld M, Nagaya M, Utikal J, Weir G, Hochedlinger K. Induced pluripotent stem cells generated without viral integration. Science. 2008;322:945-9. doi:10.1126/science.1162494

[31] Okita K, Matsumura Y, Sato Y, Okada A, Morizane A, Okamoto S, et al. A more efficient method to generate integration-free human iPS cells. Nat Methods. 2011;8:409-12. doi:10.1038/nmeth.1591

[32] Warren L, Manos PD, Ahfeldt T, Loh Y-H, Li H, Lau F, et al. Highly efficient reprogramming to pluripotency and directed differentiation of human cells with synthetic modified mRNA. Cell Stem Cell. 2010;7:618-30. doi:10.1016/j.stem.2010.08.012

[33] Kim D, Kim C-H, Moon J-I, Chung Y-G, Chang M-Y, Han B-S, et al. Generation of human induced pluripotent stem cells by direct delivery of reprogramming proteins. Cell Stem Cell. 2009;4:472-6. doi:10.1016/j.stem. 2009.05.005

[34] Hou P, Li Y, Zhang X, Liu C, Guan J, Li H, et al. Pluripotent stem cells induced from mouse somatic cells 
by small-molecule compounds. Science. 2013;341:651-4. doi:10.1126/science. 1239278

[35] Yu J, Chau KF, Vodyanik MA, Jiang J, Jiang Y. Efficient feeder-free episomal reprogramming with small molecules. PloS One. 2011;6:e17557. doi:10.1371/ journal.pone. 0017557

[36] Mattis VB, Tom C, Akimov S, Saeedian J, Østergaard ME, Southwell AL, et al. HD iPSC-derived neural progenitors accumulate in culture and are susceptible to BDNF withdrawal due to glutamate toxicity. Hum Mol Genet. 2015;24:3257-71. doi:10.1093/hmg/ddv080

[37] Tidball AM, Bryan MR, Uhouse MA, Kumar KK, Aboud AA, Feist JE, et al. A novel manganese-dependent ATM-p53 signaling pathway is selectively impaired in patient-based neuroprogenitor and murine striatal models of Huntington's disease. Hum Mol Genet. 2014:ddu609. doi:10.1093/hmg/ddu609

[38] Lu X-H, Mattis VB, Wang N, Al-Ramahi I, van den Berg N, Fratantoni SA, et al. Targeting ATM ameliorates mutant Huntingtin toxicity in cell and animal models of Huntington's disease. Sci Transl Med. 2014;6:268ra178-268ra178. doi:10.1126/scitranslmed.3010523

[39] Dickey AS, Pineda VV, Tsunemi T, Liu PP, Miranda HC, Gilmore-Hall SK, et al. PPAR- $\delta$ is repressed in Huntington's disease, is required for normal neuronal function and can be targeted therapeutically. Nat Med. 2016;22:37-45. doi:10.1038/nm.4003

[40] Juopperi TA, Kim WR, Chiang C-H, Yu H, Margolis RL, Ross CA, et al. Astrocytes generated from patient induced pluripotent stem cells recapitulate features of Huntington's disease patient cells. Mol Brain. 2012;5:17. doi:10.1186/1756-6606-5-17

[41] Szlachcic WJ, Switonski PM, Krzyzosiak WJ, Figlerowicz M, Figiel M. Huntington disease iPSCs show early molecular changes in intracellular signaling, the expression of oxidative stress proteins and the p53 pathway. Dis Model Mech. 2015;8:1047-57. doi:10.1242/dmm.019406

[42] Tidball AM, Neely MD, Chamberlin R, Aboud AA, Kumar KK, Han B, et al. Genomic instability associated with p53 knockdown in the generation of Huntington's disease human induced pluripotent stem cells. PloS One. 2016;11:e0150372. doi:10.1371/journal.pone.0150372

[43] Chiu F-L, Lin J-T, Chuang C-Y, Chien T, Chen C$\mathrm{M}$, Chen K-H, et al. Elucidating the role of the A2A adenosine receptor in neurodegeneration using neurons derived from Huntington's disease iPSCs. Hum Mol Genet. 2015;24:6066-79. doi:10.1093/hmg/ddv318

[44] An MC, O'Brien RN, Zhang N, Patra BN, De La Cruz M, Ray A, et al. Polyglutamine disease modeling: Epitope based screen for homologous recombination using CRISPR/Cas9 system. PLoS Curr. 2014;6. doi:10.1371 /currents.hd.0242d2e7ad72225efa72f6964589369a

[45] Fink KD, Deng P, Torrest A, Stewart H, Pollock K, Gruenloh W, et al. Developing stem cell therapies for juvenile and adult-onset Huntington's disease. Regen Med. 2015;10:623-46. doi:10.2217/rme.15.25

[46] Douglas I, Evans S, Rawlins MD, Smeeth L, Tabrizi SJ, Wexler NS. Juvenile Huntington's disease: A populationbased study using the General Practice Research Database. BMJ Open. 2013;3:e002085. doi:10.1136/bmjopen-2012002085

[47] Quarrell O, O’Donovan KL, Bandmann O, Strong M. The prevalence of juvenile Huntington's disease: A review of the literature and meta-analysis. PLoS Curr. 2012;4. doi:10.1371/4f8606b742ef3
[48] Killoran A, Biglan KM, Jankovic J, Eberly S, Kayson E, Oakes D, et al. Characterization of the Huntington intermediate CAG repeat expansion phenotype in PHAROS. Neurology. 2013;80:2022-7. doi:10.1212/ WNL.0b013e318294b304

[49] Niclis JC, Pinar A, Haynes JM, Alsanie W, Jenny R, Dottori $\mathrm{M}$, et al. Characterization of forebrain neurons derived from late-onset Huntington's disease human embryonic stem cell lines. Front Cell Neurosci. 2013;7. doi:10.3389/fncel.2013.00037

[50] Zhang N, Bailus BJ, Ring KL, Ellerby LM. iPSC-based drug screening for Huntington's disease. Brain Res. 2015. doi:10.1016/j.brainres.2015.09.020

[51] Mattis VB, Svendsen CN. Modeling Huntington's disease with patient-derived neurons. Brain Res. 2015. doi:10.1016/j.brainres.2015.10.001.

[52] Liu L, Huang J-S, Han C, Zhang G-X, Xu X-Y, Shen Y, et al. Induced pluripotent stem cells in Huntington's disease: Disease modeling and the potential for cell-based therapy. Mol Neurobiol. 2015:1-11. doi:10.1007/s12035015-9601-8

[53] Golas MM, Sander B. Use of human stem cells in Huntington disease modeling and translational research. Exp Neurol. 2016. doi:10.1016/j.expneurol. 2016.01.021

[54] Kaye JA, Finkbeiner S. Modeling Huntington's disease with induced pluripotent stem cells. Mol Cell Neurosci. 2013;56:50-64. doi:10.1016/j.mcn.2013.02.005

[55] Hendriks WT, Warren CR, Cowan CA. Genome editing in human pluripotent stem cells: Approaches, pitfalls, and solutions. Cell Stem Cell. 2016;18:53-65. doi:10.1016/j.stem.2015.12.002.

[56] Aubry L, Bugi A, Lefort N, Rousseau F, Peschanski M, Perrier AL. Striatal progenitors derived from human ES cells mature into DARPP32 neurons in vitro and in quinolinic acid-lesioned rats. Proc Natl Acad Sci. 2008;105:16707-12. doi:10.1073/pnas.0808488105

[57] Nicoleau C, Varela C, Bonnefond C, Maury Y, Bugi A, Aubry L, et al. Embryonic stem cells neural differentiation qualifies the role of $\mathrm{Wnt} / \beta$-Catenin signals in human telencephalic specification and regionalization. Stem Cells. 2013;31:1763-74. doi:10.1002/stem. 1462

[58] Li X-J, Zhang X, Johnson MA, Wang Z-B, Lavaute T, Zhang S-C. Coordination of sonic hedgehog and Wnt signaling determines ventral and dorsal telencephalic neuron types from human embryonic stem cells. Dev Camb Engl. 2009;136:4055-63. doi:10.1242/dev.036624

[59] El-Akabawy G, Medina LM, Jeffries A, Price J, Modo M. Purmorphamine increases DARPP-32 differentiation in human striatal neural stem cells through the Hedgehog pathway. Stem Cells Dev. 2011;20:1873-87. doi:10.1089/scd.2010.0282

[60] Ma L, Hu B, Liu Y, Vermilyea SC, Liu H, Gao $\mathrm{L}$, et al. Human embryonic stem cell-derived GABA neurons correct locomotion deficits in quinolinic acidlesioned mice. Cell Stem Cell. 2012;10:455-64. doi:10. 1016/j.stem.2012.01.021

[61] Victor MB, Richner M, Hermanstyne TO, Ransdell JL, Sobieski C, Deng P-Y, et al. Generation of human striatal neurons by MicroRNA-dependent direct conversion of fibroblasts. Neuron. 2014;84:311-23. doi:10.1016/j.neuron.2014.10.016

[62] Arber C, Precious SV, Cambray S, Risner-Janiczek JR, Kelly C, Noakes Z, et al. Activin A directs striatal projection neuron differentiation of human pluripotent stem 
cells. Dev Camb Engl. 2015;142:1375-86. doi:10.1242 $/$ dev. 117093

[63] Graveland GA, Williams RS, DiFiglia M. Evidence for degenerative and regenerative changes in neostriatal spiny neurons in Huntington's disease. Science 1985;227:770-3. doi:10.1126/science. 3155875

[64] Reiner A, Albin RL, Anderson KD, D'Amato CJ, Penney JB, Young AB. Differential loss of striatal projection neurons in Huntington disease. Proc Natl Acad Sci 1988:85:5733-7.

[65] Waclaw RR, Wang B, Pei Z, Ehrman LA, Campbell K. Distinct temporal requirements for the homeobox gene Gsx2 in specifying striatal and olfactory bulb neuronal fates. Neuron. 2009;63:451-65. doi:10.1016/j.neuron.2009.07.015

[66] Olsson M, Björklund A, Campbell K. Early specification of striatal projection neurons and interneuronal subtypes in the lateral and medial ganglionic eminence. Neuroscience. 1998;84:867-76.

[67] Onorati M, Castiglioni V, Biasci D, Cesana E, Menon R, Vuono R, et al. Molecular and functional definition of the developing human striatum. Nat Neurosci. 2014;17:180415. doi: $10.1038 / \mathrm{nn} .3860$

[68] Takahashi K, Liu F-C, Hirokawa K, Takahashi H. Expression of Foxp2, a gene involved in speech and language, in the developing and adult striatum. J Neurosci Res. 2003;73:61-72. doi:10.1002/jnr.10638

[69] Tamura S, Morikawa Y, Iwanishi H, Hisaoka T, Senba E. Foxp1 gene expression in projection neurons of the mouse striatum. Neuroscience. 2004;124:261-7. doi:10.1016/j.neuroscience.2003.11.036

[70] Fjodorova M, Noakes Z, Li M. How to make striatal projection neurons. Neurogenesis. 2015;2:e1100227. doi:10.1080/23262133.2015.1100227

[71] Lin L, Yuan J, Sander B, Golas MM. In vitro differentiation of human neural progenitor cells into striatal GABAergic neurons. Stem Cells Transl Med. 2015;4:77588. doi:10.5966/sctm.2014-0083

[72] Delli Carri A, Onorati M, Lelos MJ, Castiglioni V, Faedo A, Menon R, et al. Developmentally coordinated extrinsic signals drive human pluripotent stem cell differentiation toward authentic DARPP-32+mediumsized spiny neurons. Dev Camb Engl. 2013;140:301-12. doi: $10.1242 /$ dev.084608

[73] Yoo AS. MicroRNA-mediated conversion of human fibroblasts to neurons. Nature. 2011;476:228-31. doi:10.1038/nature 10323

[74] Studer L, Vera E, Cornacchia D. Programming and reprogramming cellular age in the era of induced pluripotency. Cell Stem Cell. 2015;16:591-600. doi:10.1016/j.stem.2015.05.004

[75] Miller JD, Ganat YM, Kishinevsky S, Bowman RL, Liu B, Tu EY, et al. Human iPSC-based modeling of lateonset disease via progerin-induced aging. Cell Stem Cell. 2013;13:691-705. doi:10.1016/j.stem.2013.11.006

[76] Liu G-H, Suzuki K, Qu J, Sancho-Martinez I, Yi F, Li M, et al. Targeted gene correction of laminopathy-associated LMNA mutations in patient-specific iPSCs. Cell Stem Cell. 2011;8:688-94. doi:10.1016/j.stem.2011.04.019

[77] Khurana V, Tardiff DF, Chung CY, Lindquist S. Toward stem cell-based phenotypic screens for neurodegenerative diseases. Nat Rev Neurol. 2015;11:339-50. doi:10.1038/nrneurol.2015.79

[78] Nguyen GD, Gokhan S, Molero AE, Mehler MF. Selective roles of normal and mutant huntingtin in neural induction and early neurogenesis. PLoS One. 2013;8:e64368. doi:10.1371/journal.pone.0064368

[79] Molina-Calavita M, Barnat M, Elias S, Aparicio E, Piel M, Humbert S. Mutant huntingtin affects cortical progenitor cell division and development of the mouse neocortex. J Neurosci. 2014;34:10034-40. doi:10.1523/JNEUROSCI.0715-14.2014

[80] Lopes C, Aubert S, Bourgois-Rocha F, Barnat M, Rego AC, Déglon N, et al. Dominant-negative effects of adultonset huntingtin mutations alter the division of human embryonic stem cells-derived neural cells. PloS One. 2016;11:e0148680. doi:10.1371/journal.pone.0148680

[81] Nopoulos P, Magnotta VA, Mikos A, Paulson H, Andreasen NC, Paulsen JS. Morphology of the cerebral cortex in preclinical Huntington's disease. Am J Psychiatry. 2007;164:1428-34. doi:10.1176/appi.ajp. 2007.06081266

[82] Paulsen JS, Nopoulos PC, Aylward E, Ross CA, Johnson H, Magnotta VA, et al. Striatal and white matter predictors of estimated diagnosis for Huntington disease. Brain Res Bull. 2010;82:201-7. doi:10.1016/ j.brainresbull.2010.04.003

[83] Aylward EH. Change in MRI striatal volumes as a biomarker in preclinical Huntington's disease. Brain Res Bull. 2007;72:152-8. doi:10.1016/j.brainresbull. 2006.10.028

[84] Wolf RC, Thomann PA, Thomann AK, Vasic N, Wolf ND, Landwehrmeyer GB, et al. Brain structure in preclinical Huntington's disease: A multi-method approach. Neurodegener Dis. 2013;12:13-22. doi:10.1159/000338635

[85] Unschuld PG, Joel SE, Liu X, Shanahan M, Margolis $\mathrm{RL}$, Biglan KM, et al. Impaired cortico-striatal functional connectivity in prodromal Huntington's disease. Neurosci Lett. 2012;514:204-9. doi:10.1016/j.neulet.2012.02.095

[86] Harrington DL, Rubinov M, Durgerian S, Mourany L, Reece C, Koenig K, et al. Network topology and functional connectivity disturbances precede the onset of Huntington's disease. Brain J Neurol. 2015;138:2332-46. doi:10.1093/brain/awv145

[87] Philpott AL, Cummins TDR, Bailey NW, Churchyard A, Fitzgerald PB, Georgiou-Karistianis N. Cortical inhibitory deficits in premanifest and early Huntington's disease. Behav Brain Res. 2016;296:311-7. doi:10.1016/j.bbr.2015.09.030

[88] Kerschbamer E, Biagioli M. Huntington's disease as neurodevelopmental disorder: Altered chromatin regulation, coding, and non-coding RNA Transcription. Front Neurosci. 2016;9. doi:10.3389/fnins.2015.00509

[89] Gómez-Tortosa E, MacDonald ME, Friend JC, Taylor SAM, Weiler LJ, Cupples LA, et al. Quantitative neuropathological changes in presymptomatic Huntington's disease. Ann Neurol. 2001;49:29-34.

[90] Unschuld PG, Joel SE, Pekar JJ, Reading SA, Oishi K, McEntee J, et al. Depressive symptoms in prodromal Huntington's disease correlate with Stroop-interference related functional connectivity in the ventromedial prefrontal cortex. Psychiatry Res Neuroimaging. 2012;203:166-74. doi:10.1016/j.pscychresns.2012.01.002

[91] Puigdellívol M, Cherubini M, Brito V, Giralt A, Suelves N, Ballesteros J, et al. A role for Kalirin-7 in corticostriatal synaptic dysfunction in Huntington's disease. Hum Mol Genet. 2015;24:7265-85. doi:10.1093/hmg/ddv426

[92] Deng YP, Wong T, Bricker-Anthony C, Deng B, Reiner A. Loss of corticostriatal and thalamostriatal synaptic terminals precedes striatal projection neuron pathology in 
heterozygous Q140 Huntington's disease mice. Neurobiol Dis. 2013;60:89-107. doi:10.1016/j.nbd.2013.08.009

[93] McKinstry SU, Karadeniz YB, Worthington AK, Hayrapetyan VY, Ozlu MI, Serafin-Molina K, et al. Huntingtin is required for normal excitatory synapse development in cortical and striatal circuits. J Neurosci. 2014;34:9455-72. doi:10.1523/JNEUROSCI.469913.2014

[94] Hickey MA, Kosmalska A, Enayati J, Cohen R, Zeitlin S, Levine MS, et al. Extensive early motor and non-motor behavioral deficits are followed by striatal neuronal loss in knock-in Huntington's disease mice. Neuroscience. 2008;157:280-95. doi:10.1016/ j.neuroscience.2008.08.041

[95] Brennand K. Is Huntington's disease a neurodevelopmental disorder? Sci Transl Med. 2016;8:320ec1-320ec1. doi:10.1126/scitranslmed.aad 9760

[96] Humbert S. Is Huntington disease a developmental disorder? EMBO Rep. 2010;11:899. doi:10.1038/ embor.2010.182

[97] Sapp E, Kegel KB, Aronin N, Hashikawa T, Uchiyama $\mathrm{Y}$, Tohyama K, et al. Early and progressive accumulation of reactive microglia in the Huntington disease brain. J Neuropathol Exp Neurol. 2001;60:161-72.

[98] Pavese N, Gerhard A, Tai YF, Ho AK, Turkheimer F, Barker RA, et al. Microglial activation correlates with severity in Huntington disease A clinical and PET study. Neurology. 2006;66:1638-43. doi:10.1212/ 01.wnl.0000222734.56412.17

[99] Singhrao SK, Thomas P, Wood JD, MacMillan JC, Neal JW, Harper PS, et al. Huntingtin protein colocalizes with lesions of neurodegenerative diseases: An investigation in Huntington's, Alzheimer's, and Pick's diseases. Exp Neurol. 1998;150:213-22. doi:10.1006/exnr.1998.6778

[100] Myers RH, Vonsattel JP, Paskevich PA, Kiely DK, Stevens TJ, Cupples LA, et al. Decreased neuronal and increased oligodendroglial densities in Huntington's disease caudate nucleus. J Neuropathol Exp Neurol. 1991;50: 729-42.

[101] Faideau M, Kim J, Cormier K, Gilmore R, Welch M, Auregan $\mathrm{G}$, et al. In vivo expression of polyglutamineexpanded huntingtin by mouse striatal astrocytes impairs glutamate transport: A correlation with Huntington's disease subjects. Hum Mol Genet. 2010;19:3053-67. doi: $10.1093 / \mathrm{hmg} / \mathrm{ddq} 212$

[102] Bradford J, Shin J-Y, Roberts M, Wang C-E, Li X$\mathrm{J}$, Li S. Expression of mutant huntingtin in mouse brain astrocytes causes age-dependent neurological symptoms. Proc Natl Acad Sci U S A. 2009;106:22480-5. doi:10.1073/pnas.0911503106

[103] Bradford J, Shin J-Y, Roberts M, Wang C-E, Sheng G, Li S, et al. Mutant huntingtin in glial cells exacerbates neurological symptoms of Huntington disease mice. J Biol Chem. 2010;285:10653-61. doi:10.1074/jbc.M109.083287

[104] Shin J-Y, Fang Z-H, Yu Z-X, Wang C-E, Li S-H, Li X-J. Expression of mutant huntingtin in glial cells contributes to neuronal excitotoxicity. J Cell Biol. 2005;171:1001-12. doi: $10.1083 /$ jcb. 200508072

[105] Jiang R, Diaz-Castro B, Looger LL, Khakh BS. Dysfunctional calcium and glutamate signaling in striatal astrocytes from Huntington's disease model mice. J Neurosci. 2016;36:3453-70. doi:10.1523/JNEUROSCI.369315.2016

[106] Tong X, Ao Y, Faas GC, Nwaobi SE, Xu J, Haustein MD, et al. Astrocyte Kir4.1 ion channel deficits contribute to neuronal dysfunction in Huntington's disease model mice. Nat Neurosci. 2014;17:694-703. doi:10.1038/nn.3691

[107] Boussicault L, Hérard A-S, Calingasan N, Petit F, Malgorn $\mathrm{C}$, Merienne $\mathrm{N}$, et al. Impaired brain energy metabolism in the BACHD mouse model of Huntington's disease: Critical role of astrocyte-neuron interactions. J Cereb Blood Flow Metab. 2014;34:150010. doi:10.1038/jcbfm.2014.110

[108] Hsiao H-Y, Chen Y-C, Huang C-H, Chen C-C, Hsu Y-H, Chen $\mathrm{H}-\mathrm{M}$, et al. Aberrant astrocytes impair vascular reactivity in Huntington disease. Ann Neurol. 2015;78:178-92. doi:10.1002/ana.24428

[109] Zhou S, Szczesna K, Ochalek A, Kobolák J, Varga E, Nemes C, et al. Neurosphere based differentiation of human iPSC improves astrocyte differentiation. Stem Cells Int. 2016;2016. doi:10.1155/2016/4937689

[110] Krencik R, Weick JP, Liu Y, Zhang Z-J, Zhang S-C. Specification of transplantable astroglial subtypes from human pluripotent stem cells. Nat Biotechnol. 2011;29:528-34. doi:10.1038/nbt.1877

[111] Emdad L, D'Souza SL, Kothari HP, Qadeer ZA, Germano IM. Efficient differentiation of human embryonic and induced pluripotent stem cells into functional astrocytes. Stem Cells Dev. 2012;21:404-10. doi:10.1089/scd.2010.0560

[112] Roybon L, Lamas NJ, Garcia AD, Yang EJ, Sattler R, Lewis VJ, et al. Human stem cell-derived spinal cord astrocytes with defined mature or reactive phenotypes. Cell Rep. 2013;4:1035-48. doi:10.1016/j.celrep.2013.06.021

[113] Zhang P-W, Haidet-Phillips AM, Pham JT, Lee Y, Huo Y, Tienari PJ, et al. Generation of GFAP::GFP astrocyte reporter lines from human adult fibroblast-derived iPS cells using zinc-finger nuclease technology. Glia. 2016;64:63-75. doi:10.1002/glia.22903

[114] Shaltouki A, Peng J, Liu Q, Rao MS, Zeng X. Efficient generation of astrocytes from human pluripotent stem cells in defined conditions. Stem Cells Dayt Ohio. 2013;31:94152. doi:10.1002/stem.1334

[115] Wang S, Bates J, Li X, Schanz S, Chandler-Militello $\mathrm{D}$, Levine $\mathrm{C}$, et al. Human iPSC-derived oligodendrocyte progenitor cells can myelinate and rescue a mouse model of congenital hypomyelination. Cell Stem Cell. 2013;12:252-64. doi:10.1016/j.stem.2012.12.002

[116] Hu B-Y, Du Z-W, Zhang S-C. Differentiation of human oligodendrocytes from pluripotent stem cells. Nat Protoc. 2009;4:1614-22. doi:10.1038/nprot.2009.186

[117] Izrael M, Zhang P, Kaufman R, Shinder V, Ella R, Amit $\mathrm{M}$, et al. Human oligodendrocytes derived from embryonic stem cells: Effect of noggin on phenotypic differentiation in vitro and on myelination in vivo. Mol Cell Neurosci. 2007;34:310-23. doi:10.1016/j.mcn.2006.11.008

[118] Czepiel M, Balasubramaniyan V, Schaafsma W, Stancic M, Mikkers H, Huisman C, et al. Differentiation of induced pluripotent stem cells into functional oligodendrocytes. Glia. 2011;59:882-92. doi:10.1002/glia.21159

[119] Marion RM, Strati K, Li H, Tejera A, Schoeftner S, Ortega $\mathrm{S}$, et al. Telomeres acquire embryonic stem cell characteristics in induced pluripotent stem cells. Cell Stem Cell. 2009;4:141-54. doi:10.1016/j.stem.2008.12.010

[120] Suhr ST, Chang EA, Rodriguez RM, Wang K, Ross PJ, Beyhan Z, et al. Telomere dynamics in human cells reprogrammed to pluripotency. PloS One. 2009;4:e8124. doi:10.1371/journal.pone.0008124

[121] Lapasset L, Milhavet O, Prieur A, Besnard E, Babled A, Aït-Hamou N, et al. Rejuvenating senescent and 
centenarian human cells by reprogramming through the pluripotent state. Genes Dev. 2011;25:2248-53. doi:10.1101/gad.173922.111

[122] Prigione A, Hossini AM, Lichtner B, Serin A, Fauler B, Megges M, et al. Mitochondrial-associated cell death mechanisms are reset to an embryoniclike state in aged donor-derived iPS cells harboring chromosomal aberrations. PloS One. 2011;6:e27352. doi:10.1371/journal.pone.0027352

[123] Goldman SA. Stem and progenitor cell-based therapy of the central nervous system: Hopes, hype, and wishful thinking. Cell Stem Cell. 2016;18:174-88. doi:10.1016/j.stem.2016.01.012

[124] Kim K, Doi A, Wen B, Ng K, Zhao R, Cahan P, et al. Epigenetic memory in induced pluripotent stem cells. Nature. 2010;467:285-90. doi:10.1038/nature09342

[125] Srikanth P, Young-Pearse TL. Stem cells on the brain: Modeling neurodevelopmental and neurodegenerative diseases using human induced pluripotent stem cells. J Neurogenet. 2014;28:5-29. doi:10.3109/01677063.2014.881358

[126] Polo JM, Liu S, Figueroa ME, Kulalert W, Eminli $\mathrm{S}$, Tan KY, et al. Cell type of origin influences the molecular and functional properties of mouse induced pluripotent stem cells. Nat Biotechnol. 2010;28:848-55. doi: $10.1038 /$ nbt. 1667

[127] Mikkelsen TS, Hanna J, Zhang X, Ku M, Wernig $\mathrm{M}$, Schorderet $\mathrm{P}$, et al. Dissecting direct reprogramming through integrative genomic analysis. Nature. 2008;454:49-55. doi:10.1038/nature07056

[128] Kang X, Yu Q, Huang Y, Song B, Chen Y, Gao X, et al. Effects of integrating and non-integrating reprogramming methods on copy number variation and genomic stability of human induced pluripotent stem cells. PLoS One. 2015;10:e0131128. doi:10.1371/journal.pone.0131128

[129] Laurent LC, Ulitsky I, Slavin I, Tran H, Schork A, Morey R, et al. Dynamic changes in the copy number of pluripotency and cell proliferation genes in human ESCs and iPSCs during reprogramming and time in culture. Cell Stem Cell. 2011;8:106-18. doi:10.1016/j.stem.2010.12.003

[130] Lister R, Pelizzola M, Kida YS, Hawkins RD, Nery JR, Hon $\mathrm{G}$, et al. Hotspots of aberrant epigenomic reprogramming in human induced pluripotent stem cells. Nature. 2011;471:68-73. doi:10.1038/nature09798

[131] Ruiz S, Lopez-Contreras AJ, Gabut M, Marion RM, Gutierrez-Martinez P, Bua S, et al. Limiting replication stress during somatic cell reprogramming reduces genomic instability in induced pluripotent stem cells. Nat Commun. 2015;6:8036. doi:10.1038/ncomms9036

[132] Hussein SM, Batada NN, Vuoristo S, Ching RW, Autio R, Närvä E, et al. Copy number variation and selection during reprogramming to pluripotency. Nature. 2011;471:58-62. doi:10.1038/nature09871

[133] Ritch JJ, Valencia A, Alexander J, Sapp E, Gatune L, Sangrey GR, et al. Multiple phenotypes in Huntington disease mouse neural stem cells. Mol Cell Neurosci. 2012;50:70-81. doi:10.1016/j.mcn.2012.03.011
[134] McNeish J, Gardner JP, Wainger BJ, Woolf CJ, Eggan K. From dish to bedside: Lessons learned while translating findings from a stem cell model of disease to a clinical trial. Cell Stem Cell. 2015;17:8-10. doi:10.1016/j.stem.2015.06.013

[135] Hargus G, Ehrlich M, Hallmann A-L, Kuhlmann T. Human stem cell models of neurodegeneration: A novel approach to study mechanisms of disease development. Acta Neuropathol (Berl). 2014;127:151-73. doi:10.1007/s00401-013-1222-6

[136] Imaizumi Y, Okano H. Modeling human neurological disorders with induced pluripotent stem cells. J Neurochem. 2014;129:388-99. doi:10.1111/jnc. 12625

[137] Vasileva EA, Shuvalov OU, Garabadgiu AV, Melino G, Barlev NA. Genome-editing tools for stem cell biology. Cell Death Dis. 2015;6:e1831. doi:10.1038/cddis.2015.167

[138] Li M, Suzuki K, Kim NY, Liu G-H, Izpisua Belmonte JC. A cut above the rest: Targeted genome editing technologies in human pluripotent stem cells. J Biol Chem. 2014;289:4594-9. doi:10.1074/jbc.R113.488247

[139] Veres A, Gosis BS, Ding Q, Collins R, Ragavendran A, Brand $\mathrm{H}$, et al. Low incidence of off-target mutations in individual CRISPR-Cas9 and TALEN targeted human stem cell clones detected by wholegenome sequencing. Cell Stem Cell. 2014;15:27-30. doi:10.1016/j.stem.2014.04.020

[140] Jonson I, Ougland R, Larsen E. DNA repair mechanisms in Huntington's disease. Mol Neurobiol. 2013;47:1093-102. doi:10.1007/s12035-013-8409-7

[141] Musunuru K. Genome editing of human pluripotent stem cells to generate human cellular disease models. Dis Model Mech. 2013;6:896-904. doi:10.1242/dmm.012054

[142] Reinhardt P, Schmid B, Burbulla LF, Schöndorf DC, Wagner L, Glatza M, et al. Genetic correction of a LRRK2 mutation in human iPSCs links parkinsonian neurodegeneration to ERK-dependent changes in gene expression. Cell Stem Cell. 2013;12:354-67. doi:10.1016/j.stem.2013.01.008

[143] Bradley CK, Scott HA, Chami O, Peura TT, Dumevska B, Schmidt U, et al. Derivation of Huntington's diseaseaffected human embryonic stem cell lines. Stem Cells Dev. 2010;20:495-502. doi:10.1089/scd.2010.0120

[144] Feyeux M, Bourgois-Rocha F, Redfern A, Giles P, Lefort $\mathrm{N}$, Aubert $\mathrm{S}$, et al. Early transcriptional changes linked to naturally occurring Huntington's disease mutations in neural derivatives of human embryonic stem cells. Hum Mol Genet. 2012;21:3883-95. doi:10.1093/hmg/dds216

[145] Jacquet L, Neueder A, Földes G, Karagiannis P, Hobbs $\mathrm{C}$, Jolinon N, et al. Three Huntington's disease specific mutation-carrying human embryonic stem cell lines have stable number of CAG repeats upon in vitro differentiation into cardiomyocytes. PLoS One. 2015;10. doi:10.1371/journal.pone. 0126860 